IAÇANÃ VALENTE FERREIRA GONZAGA

Gama-orizanol para equinos

Pirassununga

2013 


\section{Gama-orizanol para equinos}

Tese apresentada ao Programa de Pós-Graduação em Nutrição e Produção Animal da Faculdade de Medicina Veterinária e Zootecnia da Universidade de São Paulo para obtenção do título de Doutora em Ciências

\section{Departamento:}

Nutrição e Produção Animal

Área de concentração:

Nutrição e Produção Animal

\section{Orientador:}

Prof. Dr. Alexandre Augusto de Oliveira Gobesso

Pirassununga 
Autorizo a reprodução parcial ou total desta obra, para fins acadêmicos, desde que citada a fonte.

\section{DADOS INTERNACIONAIS DE CATALOGAÇÃO-NA-PUBLICAÇÃO}

(Biblioteca Virginie Buff D’Ápice da Faculdade de Medicina Veterinária e Zootecnia da Universidade de São Paulo)

Gonzaga, Iaçanã Valente Ferreira

Gama-orizanol para equinos / Iaçanã Valente Ferreira Gonzaga. -- 2013

85 f. : il.

Tese (Doutorado) - Universidade de São Paulo. Faculdade de Medicina Veterinária e Zootecnia. Departamento de Nutrição e Produção Animal, Pirassununga, 2013.

Programa de Pós-Graduação: Nutrição e Produção Animal.

Área de concentração: Nutrição e Produção Animal.

Orientador: Prof. Dr. Alexandre Augusto de Oliveira Gobesso.

1. Cavalos. 2. Exercício. 3. Frequência cardíaca. 4. Gama-orizanol. 5. Ultrassonografia. I. Título. 
UNIVERSIDADE DE SÃO PAULO

\section{Comissão de Ética no uso de animais}

\section{CERTIFICADO}

Certificamos que o Projeto intitulado: "Avaliação da resposta a suplementação com gama-orizanol em eqüinos submetidos a exercício físico", protocolado sob o n $1794 / 2009$, utilizando 16 (dezesseis) cavalos, sob a responsabilidade do Prof. Dr. Alexandre Augusto de Oliveira Gobesso, está de acordo com os princípios éticos de experimentação animal da "Comissão de Ética no uso de anịmais" da Faculdade de Medicina Veterinária e Zootecnia da Universidade de São Paulo e foi aprovado em reunião de 20/01/2010.

We certify that the Research "Supplementation response evaluation with gamaoryzanol in equine subjected to physical exercise", protocol number 1794/2009, utilizing 16 (sixteen) horses, under the responsibility Prof. Dr. Alexandre Augusto de Oliveira Gobesso, agree with Ethical Principles in Animal Research adopted by "Ethic Committee in the use of animals" of the School of Veterinary Medicine and Animal Science of University of São Paulo was approved in the meeting of day $01 / 20 / 2010$.

São Paulo, 21 de janeiro de 2010

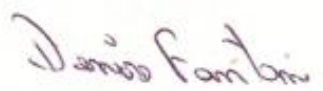

Profa Dra Denise Tabacchi Fantoni Presidente 


\section{FOLHA DE AVALIAÇÃO}

Nome: GONZAGA, Iaçanã Valente Ferreira

\section{Título: Gama-orizanol para equinos}

Tese apresentada ao Programa de Pós-Graduação em Nutrição e Produção Animal da Faculdade de Medicina Veterinária e Zootecnia da Universidade de São Paulo para obtenção do título de Doutora em Ciências

Data:

\section{Banca Examinadora}

Prof. Dr.

Instituição: Julgamento:

Prof. Dr.

Instituição: Julgamento:

Prof. Dr.

Instituição: Julgamento:

Prof. Dr.

Instituição: Julgamento:

Prof. Dr.

Instituição: Julgamento: 
Dedico este trabalho aos meus pais,

Luiz Gonzaga e Mirtes Fátima Ferreira Gonzaga. 


\section{AGRADECIMENTOS}

Agradeço a meus pais pelo amor e apoio dispensado mesmo estando distante;

A toda minha família, em especial à minha madrinha Selma Adízia (in memorian);

Ao meu orientador Prof. Alexandre A. O. Gobesso por toda confiança depositada, agradeço a todos os ensinamentos e oportunidades, além de muita paciência;

A todos os docentes, amigos e funcionários do Departamento de Nutrição e Produção Animal (VNP), de toda FMVZ e FZEA, e da Prefeitura do Campus Administrativo de Pirassununga;

A Esther Raspantini e Paulo César do Ceptox, por cada dia de pesagem, de cada saquinho de gama-orizanol;

Ao amigo Roberto Diaz Martins (Bobi), pelo auxílio nas avaliações ultrassonográficas;

Ao Prof. Marcos Veiga, pelo empréstimo do equipamento de ultrassom;

A Aline Nova e todos do Departamento de Fisiologia da Escola de Educação Física e do Esporte da Universidade de São Paulo;

A Fundação de Amparo à Pesquisa do Estado de São Paulo (FAPESP) e à Coordenadoria e Aperfeiçoamento do Pessoal de Nível Superior (CAPES) pelo apoio financeiro;

Aos Professores José Nicolau P. Puoli-Filho e Ricardo de Albuquerque por participarem da minha banca de qualificação, sendo de grande importância para o aperfeiçoamento deste material;

Aos meus eternos irmãos Labequianos Henry, Fernanda Taran, Rafael e Camilla, e aos mais novos Labequianos Mayara, Kátia, Paulo Sanchez, Marcelo, Luís, Laís, Regina e Bia entre todos os outros que possa não ter lembrado;

Aos alunos de iniciação científica Júlia, Fernanda Rodrigues, Yasmin e Mariana, fundamentais durante a avaliação cardíaca dos animais naqueles sábados sem fim no Labequi; e também aos mais novos Michelle, Érica e Diovani;

A todos os meus amigos, que são minha família em Pirassununga, dentre tantos, vocês sabem quem são... Lambaris, Sapés, Garnizés... me perdoem se esqueci de alguém;

E finalmente a quem mais me ajudaram.....os cavalos! Sem eles nenhuma linha aqui faria sentido, Brittan, Maximus, Malcon, Taleeze, Darius, Jazz, L’espoir, Jaffar, Shawan e Ramsey. Obrigada também aos Mini-horses e ao Nemo pelo apoio moral. 
"Viva como se fosse morrer amanhã, aprenda como se fosse viver para sempre".

(Mahatma Gandhi) 


\section{RESUMO}

GONZAGA, I. V. F. Gama-orizanol para equinos. [Gamma-oryzanol for horses]. 2013. 85 f. Tese (Doutorado em Ciências) - Faculdade de Medicina Veterinária e Zootecnia, Universidade de São Paulo, Pirassununga, 2013.

Com o objetivo de avaliar o efeito da suplementação com gama-orizanol em equinos submetidos a exercício aeróbio foram utilizados 10 cavalos da raça Puro Sangue Árabe, machos, castrados, com idade média de $35 \pm 8,15$ meses e peso corporal médio de $375 \pm 22,78$ $\mathrm{kg}$, ao início do período experimental, divididos em dois lotes de cinco animais cada, denominados grupos "controle" e "gama". O experimento foi conduzido no Laboratório de Pesquisa em Alimentação e Fisiologia do Exercício de Equinos (LABEQUI), pertencente à FMVZ-USP, no Campus Administrativo de Pirassununga, São Paulo, adotando-se o consumo diário individual de $2 \%$ do peso corpóreo, com base na matéria seca, sendo $50 \%$ de volumoso composto por feno de gramínea e 50\% de concentrado comercial. Em cada refeição, todos os animais receberam $50 \mathrm{~mL}$ de óleo vegetal, sendo que apenas o grupo gama recebeu o gamaorizanol (dez gramas diárias). Ambos os grupos foram exercitados em caminhador circular, durante 60 minutos, na velocidade máxima de $12 \mathrm{~km} / \mathrm{h}$, cinco vezes por semana. Durante o período experimental de seis meses, os cavalos foram mensalmente avaliados quanto ao ganho de peso, escore de condição corporal, frequência cardíaca e lipídeos plasmáticos (colesterol total e frações HDL-C, VLDL-C, LDL-C; e triglicérides). A cada quarenta e cinco dias foram realizadas mensurações ultrasonográficas da espessura da camada muscular e adiposa do músculo Longissimus dorsi, e da espessura da camada de gordura na região de inserção da cauda. Foi utilizado o delineamento inteiramente casualizado com medidas repetidas no tempo. Em relação ao peso corporal ou às medidas ultrassonográficas não foi observada diferença entre os grupos, porém foi verificada redução do escore corporal, com redução ao longo do tempo $(\mathrm{p}=0,04)$ de $10 \%$ para o grupo gama quando comparado com o grupo controle $(6,5 \%)$. A concentração de colesterol total foi maior $(\mathrm{p}=0,001)$ para o grupo gama $(113,99 \mathrm{mg} / \mathrm{dL})$ do que o grupo controle $(108,55 \mathrm{mg} / \mathrm{dL})$. Em relação à frequência cardíaca (FC) foram observados efeitos de tempo para a FC basal $(p=0,001)$, final $(p=0,003)$, e ao final do exercício após $10(\mathrm{p}<0,001)$ e $20(\mathrm{p}=0,009)$ minutos. A FC após 20 minutos também demonstrou interação tempo*tratamento $(\mathrm{p}=0,05)$, onde o grupo gama obteve menor média (46,03 bpm) do que o grupo controle (46,21bpm), e ao longo dos 180 dias a média 
desta variável reduziu em $30 \%$ para o grupo gama em relação ao controle (7\%). A suplementação com gama-orizanol de equinos submetidos a exercício aeróbio pode proporcionar redução do escore de condição corporal, elevar a concentração de colesterol plasmático e pode melhorar a recuperação da frequência cardíaca após o esforço.

Palavras-chave: Cavalos. Exercício. Frequência cardíaca. Gama-orizanol. Ultrassonografia. 


\begin{abstract}
GONZAGA, I. V. F. Gamma-oryzanol for horses [Gama-orizanol para equinos]. 2013. 85 f. Tese (Doutorado em Ciências) - Faculdade de Medicina Veterinária e Zootecnia, Universidade de São Paulo, Pirassununga, 2013.
\end{abstract}

In order to evaluate the effect of supplementation with gamma-oryzanol in horses undergoing aerobic exercise were used ten Purebred Arabian horses, geldings, mean age $35 \pm 8.15$ months and mean weight of $375 \pm 22.78 \mathrm{~kg}$ at the beginning of the experimental period, divided into two groups of five animals each, named "gamma" and "control" groups. The experiment was conducted at the Laboratório de Pesquisa em Alimentação e Fisiologia do Exercício de Equinos (LABEQUI), belonging to FMVZ-USP, at Campus Administrativo de Pirassununga, São Paulo, adopting individual daily consumption of $2 \%$ of body weight, based on dry matter, $50 \%$ of forage composed of grass hay and $50 \%$ commercial concentrate. In each meal, the animals received fifty milliliters of vegetable oil, and only the gamma group received the gamma-oryzanol (ten grams daily). Both groups were trained in electronic walker for sixty minutes at a maximum speed of $12 \mathrm{~km} / \mathrm{h}$, five times a week. During the trial period of six months, the horses were evaluated monthly to weight gain, body condition score, and plasma lipids (total cholesterol and HDL-C, VLDL-C, LDL-C, and triglycerides). The every fortyfifth days were performed ultrasonographic measurements of the thickness of muscle and adipose Longissimus dorsi, and the thickness of the fat layer at the insertion of the tail. We obtained heart rates (HR) at baseline, during maximal work (HR peak), final HR and HR at 10 and 20 minutes after the end of the exercise. We used a completely randomized design with repeated measures and significance level was $10 \%$. In relation to body weight or measure ultrasound there was no difference between the groups, but was observed reduction of body condition score, reducing over time $(\mathrm{p}=0,04)$ of $10 \%$ for the gamma group when compared with the control group $(6.5 \%)$. The total cholesterol concentration was higher $(p=0.001)$ for the gamma group (113.99 $\mathrm{mg} / \mathrm{dL})$ than the control group $(108.55 \mathrm{mg} / \mathrm{dL})$. Regarding the heart rate $(\mathrm{HR})$ effects were observed over the time baseline HR $(\mathrm{p}=0.001)$, final $(\mathrm{p}=0.003)$, and at the end of exercise after $10(\mathrm{p}<0.001)$ and $20(\mathrm{p}=0.009)$ minutes. The HR after 20 minutes also showed interaction time*treatment $(\mathrm{p}=0.05)$, the gamma group had lower average $(46.03$ $\mathrm{bpm})$ than the control group $(46.21 \mathrm{bpm})$, and over the 180 days the average this variable reduced by $30 \%$ for the gamma compared to control group $(7 \%)$. Supplementation with 
gamma-oryzanol in horses undergoing aerobic exercise can provide a reduction of body condition score, raising the concentration of plasma cholesterol and can improve heart rate recovery after exercise.

Keywords: Exercise. Heart rate. Horses. Gamma-oryzanol. Ultrasound. 


\section{LISTA DE FIGURAS}

Figura 1 - Estrutura do gama-orizanol............................................................. 24

Figura 2 - $\quad$ Teor de gama-orizanol de acordo com o tipo de refino......................... 25

Figura 3 - $\quad$ Estrutura química do colesterol e fitosteróis..................................... 26

Apêndice D, Locais de avaliação do escore corporal................................................... 67

Figura 1 -

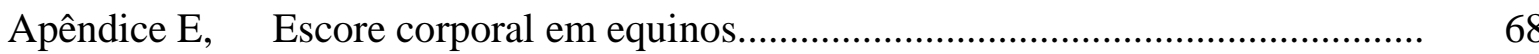

Quadro 1 -

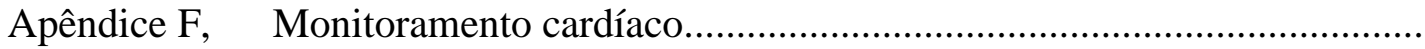

Figura 2 -

Apêndice H, Frequência cardíaca basal (FC basal), em batimentos por minuto Figura 3 - $\quad$ (bpm), ao longo do tempo para os grupos controle e gama...................

Apêndice J, Frequência cardíaca final (FC final), em batimentos por minuto Figura 4 - (bpm), ao longo do tempo para os grupos controle e gama....

Apêndice L, Frequência cardíaca de recuperação, em batimentos por minuto Figura 5 - $\quad(\mathrm{bpm}), 10$ minutos após o final do exercício $(\mathrm{FC}+10)$ ao longo do tempo para os grupos controle e gama

Apêndice N, Frequência cardíaca de recuperação, em batimentos por minuto Figura 6 - $\quad(\mathrm{bpm}), 20$ minutos após o final do exercício $(\mathrm{FC}+20)$ ao longo do tempo para os grupos controle e gama

Apêndice $\mathrm{O}, \quad$ Frequência cardíaca (FC) média dos grupos controle e gama ao longo Figura 7 - do período experimental no estágio 1 , a $7 \mathrm{Km} / \mathrm{h}$.

Apêndice $\mathrm{P}, \quad$ Frequência cardíaca (FC) média dos grupos controle e gama ao longo Figura 8 - do período experimental no estágio 2, a $10 \mathrm{Km} / \mathrm{h}$

Apêndice Q, Frequência cardíaca (FC) média dos grupos controle e gama ao longo Figura 9 - do período experimental no estágio 3, a $12 \mathrm{Km} / \mathrm{h}$ 
Apêndice R, Frequência cardíaca (FC) média dos grupos controle e gama ao longo Figura 10 - do período experimental no estágio 4, a $12 \mathrm{Km} / \mathrm{h}$................................

Apêndice S, Frequência cardíaca (FC) média dos grupos controle e gama ao longo

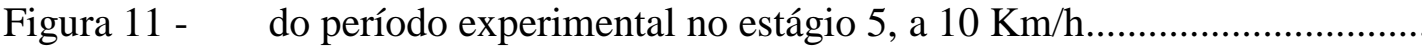

Apêndice T, Frequência cardíaca (FC) média dos grupos controle e gama ao longo

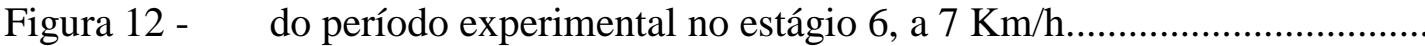

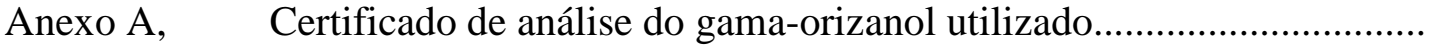

Figura 1 - 


\section{LISTA DE TABELAS}

Tabela 1 - Peso médio, ganho de peso (GP), ganho médio diário (GMD), e porcentagem $(\%)$ de ganho de peso total e diária para os grupos controle e gama ao final do período experimental.

Tabela 2 - Média de escore de condição corporal, erro padrão da média (EPM) e valor de p para os tratamentos controle e gama.

Tabela 3 - Médias de escore de condição corporal para os grupos controle e gama ao longo do período experimental.

Tabela 4 - Valores médios das medidas ultrasonográficas (em milímetros), erro padrão da média (EPM) e valor de significância para os grupos controle e gama.

Tabela 5 - Médias de colesterol total, triglicérides, HDL-C, LDL-C e VLDL-C $(\mathrm{mg} / \mathrm{dL})$, erro padrão da média (EPM) e valor de p para os tratamentos controle e gama.

Tabela 6 - Médias de frequência cardíaca (FC) (em batimentos por minuto bpm), erro padrão da média (EPM) e valor de significância para os grupos controle e gama

Tabela 7 - Médias de frequência cardíaca (bpm) dos grupos gama e controle nos diferentes estágios de exercício, erro padrão da média (EPM) e valor de $p$

Apêndice A, Divisão dos animais segundo tratamento, peso (kg) e idade (meses) no Tabela 1 - início do período experimental

Apêndice B, Análise bromatológica do feno de gramínea utilizado

Tabela 2 -

Apêndice C, Análise bromatológica do concentrado comercial utilizado 
Apêndice G, Médias e desvio padrão da frequência cardíaca basal (em batimentos Tabela 4 - por minuto) do grupo controle e suplementado (gama), em função do tempo durante o período experimental....................................................

Apêndice I, Médias e desvio padrão da frequência cardíaca final (em batimentos Tabela 5 - por minuto) do grupo controle e suplementado (gama), em função do

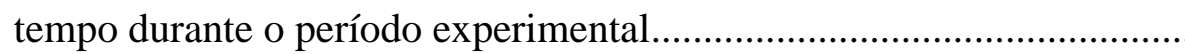

Apêndice K, Médias e desvio padrão da frequência cardíaca de recuperação, 10 Tabela 6 - minutos após o fim do exercício (em batimentos por minuto) do grupo controle e suplementado (gama), em função do tempo durante o período experimental

Apêndice M, Médias e desvio padrão da frequência cardíaca de recuperação, 20 Tabela 8 - minutos após o fim do exercício (em batimentos por minuto) do grupo controle e suplementado (gama), em função do tempo durante o período experimental. 


\section{LISTA DE ABREVIATURAS E SIGLAS}

\begin{tabular}{|c|c|}
\hline bpm & batimentos por minuto \\
\hline DP & desvio padrão \\
\hline ECC & escore de condição corporal \\
\hline EGC & espessura de gordura de cauda \\
\hline EGL & espessura de gordura lombar \\
\hline EML & espessura de músculo lombar \\
\hline FC & frequência cardíaca \\
\hline FEI & Federação Equestre Internacional \\
\hline $\mathrm{GH}$ & hormônio do crescimento \\
\hline GnRH & hormônio liberador de gonadotrofinas \\
\hline GPS & sistema de posicionamento global (global positioning system) \\
\hline h & horas \\
\hline HDL-C & fração do colesterol na lipoproteína de densidade alta \\
\hline $\mathrm{kg}$ & quilograma \\
\hline $\mathrm{Km}$ & quilômetro \\
\hline LDL-C & fração do colesterol na lipoproteína de densidade baixa \\
\hline LH & hormônio luteinizante \\
\hline $\mathrm{mg}$ & miligrama \\
\hline $\mathrm{MHz}$ & megahertz \\
\hline $\min$ & minuto \\
\hline $\mathrm{mL}$ & mililitro \\
\hline $\mathrm{mm}$ & milímetro \\
\hline $\mathrm{p}$ & nível de significância \\
\hline RPM & rotações por minuto \\
\hline US & ultrassonografia \\
\hline
\end{tabular}




\section{LISTA DE SÍMBOLOS}

$\begin{array}{ll}\Delta & \text { ciclo } \\ \gamma & \text { gama } \\ \beta & \text { beta } \\ \alpha & \text { alfa } \\ \mathrm{x} & \text { vezes } \\ { }^{\circ} \mathrm{C} & \text { graus Celsius } \\ { }^{\circledR} & \text { marca registrada } \\ \pm & \text { mais ou menos } \\ = & \text { igual } \\ < & \text { menor que } \\ < & \text { menor } \\ \% & \text { percentagem }\end{array}$




\section{SUMÁRIO}

1 INTRODUÇÃO GERAL ............................................................................................................... 21

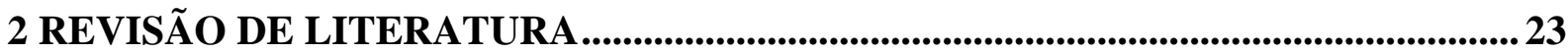

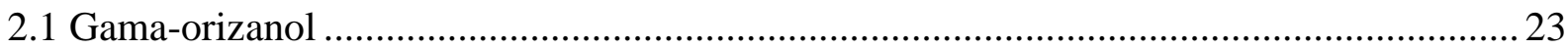

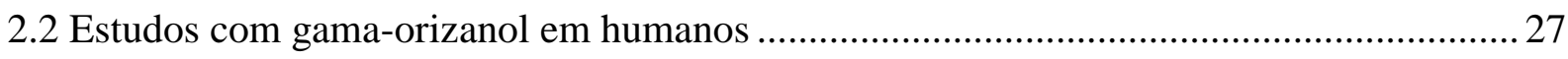

2.3 Estudos com gama-orizanol em roedores ................................................................... 28

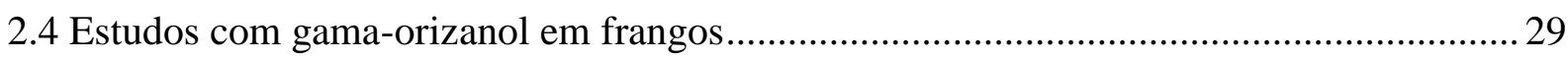

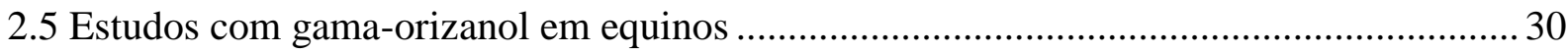

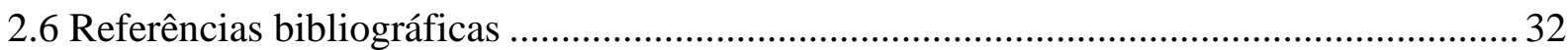

CAPÍTULO I - EFEITO DA SUPLEMENTAÇÃO COM GAMA-ORIZANOL SOBRE O DESEMPENHO DE EQUINOS SUBMETIDOS A EXERCÍCIO AERÓBIO ..............36

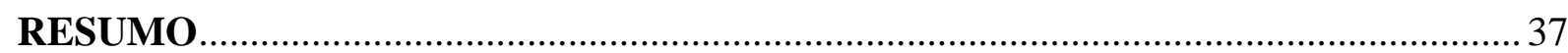

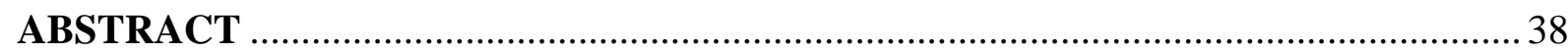

3 INTRODUÇÃO

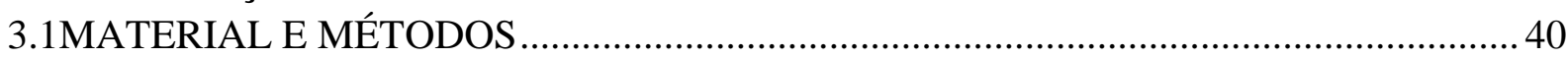

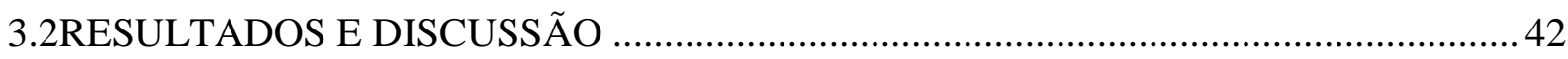

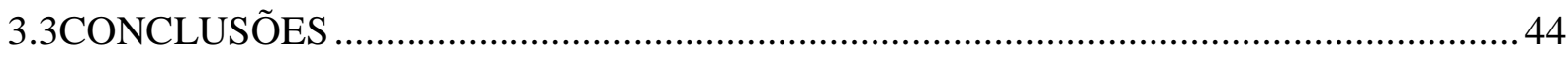

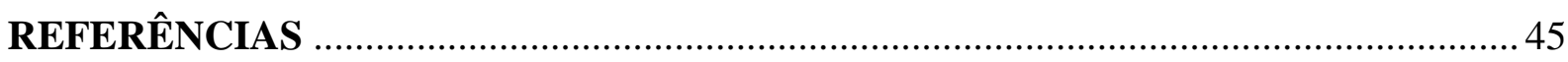

CAPÍTULO II - FREQUÊNCIA CARDÍACA DE EQUINOS SUBMETIDOS AO EXERCÍCIO AERÓBIO E SUPLEMENTADOS COM GAMA-ORIZANOL .................49

RESUMO

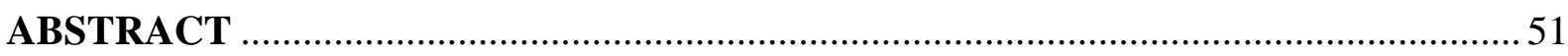

4 INTRODUÇÃO

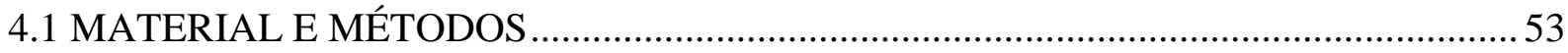

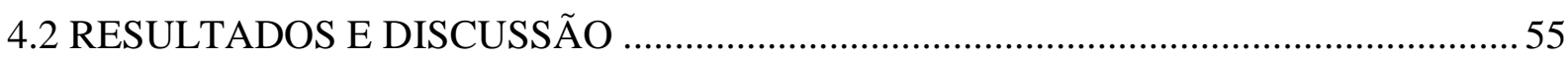

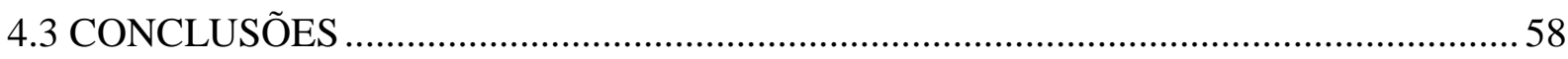

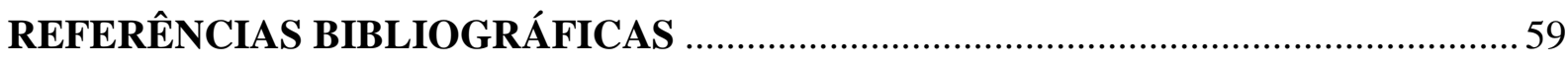

5 CONCLUSÕES GERAIS .................................................................................................. 61

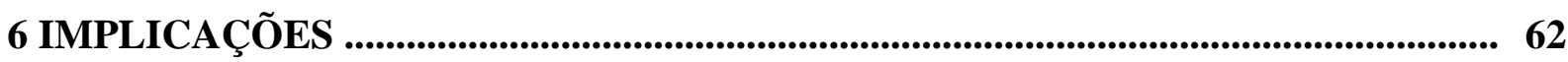

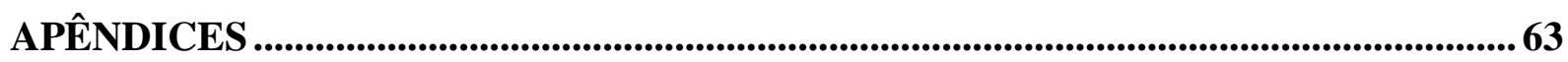

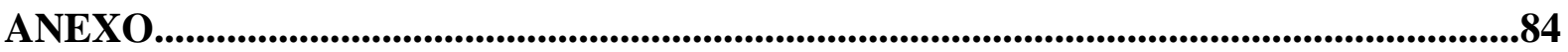




\section{INTRODUÇÃO GERAL}

A utilização de suplementos nutricionais e/ou ergogênicas tem sido amplamente difundida no meio equestre. De acordo com o dicionário de língua portuguesa Michaelis (2013), a definição da palavra ergogênico significa: "aquele que aumenta a capacidade para o trabalho corporal ou mental, especialmente pela eliminação de sintomas de fadiga". Segundo Geor (2008), o auxílio ergogênico tem sido utilizado em referência a manipulações que têm o propósito de aumentar o desempenho atlético, tais como aumento na velocidade, resistência ou força.

Substâncias ergogênicas podem ser classificadas em diferentes categorias, incluindo fatores mecânicos (utilização de dilatadores nasais externos), agentes farmacológicos (esteroides anabolizantes e eritropoietina), além de melhoras fisiológicas (através do condicionamento físico), e suplementos nutricionais ou dietas específicas (adaptação a uma dieta rica em gordura, por exemplo). Um destes princípios ativos é o gama-orizanol. Suas atividades antioxidantes e hipocolesterolêmicas já foram demonstradas em vários estudos ao redor do mundo. Fisiculturistas consomem este suplemento na esperança de incremento na massa muscular e rendimento esportivo, existindo empresas especializadas na produção e venda de gama-orizanol com essa finalidade.

Semelhante ao que ocorre com os humanos, no segmento equestre é cada vez maior a participação desta substância no mercado, seja na composição de concentrados contendo farelo de arroz, óleo de farelo de arroz, como ainda na composição de "bisnagas energéticas" para administração oral. Segundo Lima et al. (2006), o Brasil possui o maior rebanho de equinos na América Latina, sendo o terceiro mundial. Somados aos muares e asininos são oito milhões de cabeças, movimentando $\mathrm{R} \$ 7,3$ bilhões somente com a produção de cavalos. $\mathrm{O}$ rebanho envolve mais de 30 segmentos, distribuídos entre insumos, criação e destinação final e compõe a base do chamado Complexo do Agronegócio Cavalo, responsável pela geração de 3,2 milhões de empregos diretos e indiretos. O segmento de equinos utilizados em diversas atividades esportivas movimenta valores da ordem de $\mathrm{R} \$ 705$ milhões e emprega cerca de 20.500 pessoas, com a participação estimada de 50 mil atletas.

Ao contrário dos estudos realizados em outras espécies, pouco se conhece sobre as ações do gama-orizanol no organismo equino. Dessa forma, se faz necessário realizar maior número de pesquisas envolvendo a suplementação dietética de equinos com gama-orizanol, 
com o intuito de se observar os efeitos desta substância, sobretudo em animais submetidos à atividade física, já que sua utilização está ligada principalmente ao segmento esportivo. 


\section{REVISÃO DE LITERATURA}

\subsection{Gama-orizanol}

O gama-orizanol foi descoberto no óleo de arroz em 1954 por Kaneko e Tsuchiya, no Japão, sendo inicialmente descrito como um único elemento, mas estudos subsequentes revelaram que ele não é uma substância simples, e sim uma variedade de esteril ferulatos chamados de $\alpha, \beta$ e $\gamma$-orizanol (SCAVARIELLO; ARELLANO, 1998). Destes, o gamaorizanol tem sido o mais estudado devido às suas propriedades benéficas à saúde, tais como redução do colesterol plasmático (LICHENSTEIN et al., 1994), inibição da agregação plaquetária e aumento na excreção fecal de ácidos biliares (SEETHARAMAIAH et al., 1990), além da redução na absorção do colesterol e da arteriosclerose precoce (RONG et al., 1997). O gama-orizanol também tem sido utilizado na indústria farmacêutica e cosmética, assim como aditivo de alimentos, devido às suas propriedades antioxidativas (JULIANO et al., 2005).

Os componentes do gama-orizanol foram isolados e identificados por $\mathrm{Xu}$ e Godber (1999), como $\triangle^{7}$-estimastenil ferulato, estigmasteril ferulato, cicloarteril ferulato, 24metileno cicloartanil ferulato, $\triangle^{7}$-campestenil ferulato, campesteril ferulato, $\triangle^{7}$-sitostenil ferulato, sitosteril ferulato, campestanil ferulato e sitostanil ferulato e estão ilustrados na figura 1. 

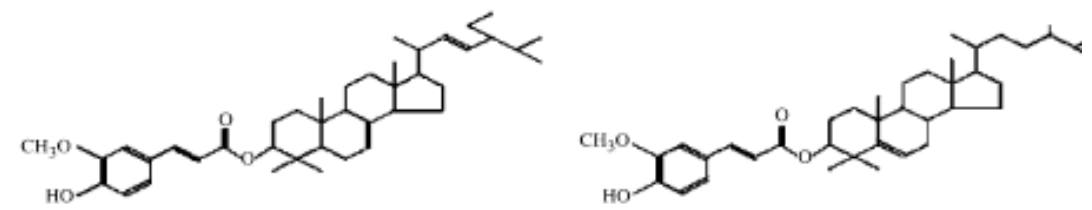

(1) $\Delta^{7}$-Stigmastenyl ferulate

(6) Campesteryl ferulate

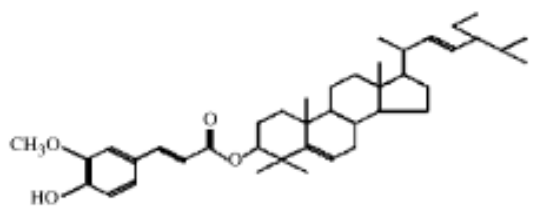

(2) Stigmasteryl ferulate

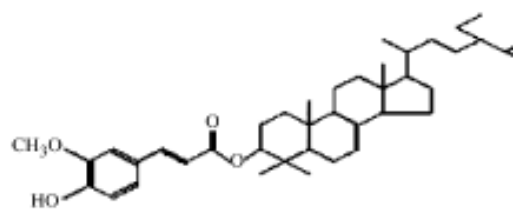

(7) $\Delta^{7}$-Sitostenyl ferulate

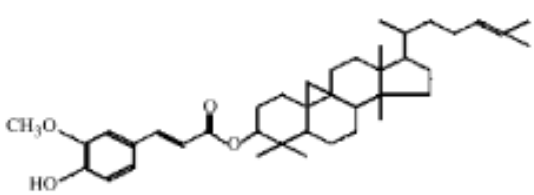

(3) Cycloartenyl ferulate

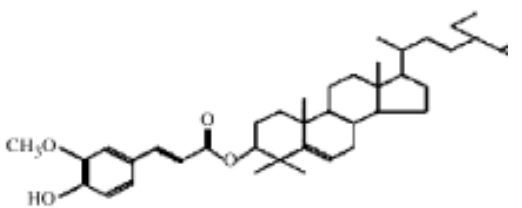

(8) Sitosteryl ferulate

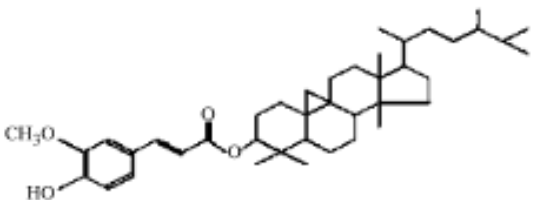

(4) 24-Methylene cycloartanyl ferulate

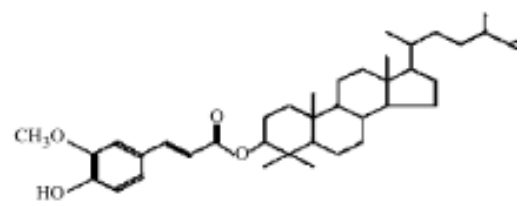

(9) Campestanyl ferulate

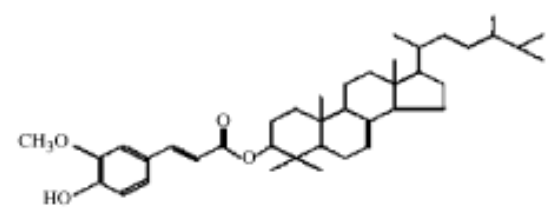

(5) $\Delta^{7}$-Campestenyl ferulate

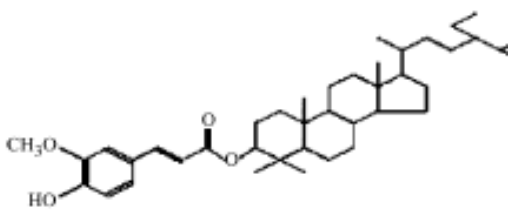

(10) Sitostanyl ferulate

Fonte: (XU; GODBER, 1999)

O teor de gama-orizanol difere de acordo com a fonte do óleo de arroz, variando de 115 a 780 ppm, dependendo do grau e método de processamento (ROGERS et al., 1993).

O óleo de arroz é subproduto das indústrias de beneficiamento de arroz (Oryza sativa), quando é realizada a separação e o processamento de derivados da casca, farelo e gérmen do endosperma do grão. $\mathrm{O}$ arroz é um dos mais importantes cereais produzidos no mundo, principalmente na Ásia e América Latina, onde a maior parte da população tem no arroz a base da sua alimentação. Devido à grande produção de arroz em muitos países, o óleo de arroz representa um grande potencial a ser explorado para produção de óleo comestível. Seu teor de óleo varia de 15 até $28 \%$ dependendo da qualidade e tipo de farelo extraído do grão. Existem dois tipos de farelo de arroz: farelo de arroz parboilizado, obtido do beneficiamento 
de arroz parboilizado - com $20 \%$ a $28 \%$ de óleo; e farelo de arroz branco, obtido do beneficiamento de arroz branco - com 15\% a 20\% de óleo (MORETTO; FETT, 1998).

As condições de processamento durante o refino e as variações sazonais na composição do óleo direcionam o tipo e a quantidade de impurezas extraídas com os compostos saponificados. As impurezas também podem afetar as condições de processamento e dificultarem as etapas de beneficiamento, como extração, isolamento e purificação (NARAYAN et al., 2006).

O teor final de gama-orizanol obtido também é afetado pelo método de extração do óleo. Durante o refino alcalino (deacidificação), com alta adição de hidróxido de sódio, o gama-orizanol é transferido para os compostos saponificados, juntamente com os sais de sódio, e seus benefícios nutricionais são perdidos. Por outro lado, o óleo de arroz refinado fisicamente, mantém aproximadamente $66 \%$ do orizanol, possuindo resposta plasmática lipídica similar àquela do óleo bruto. Experimentos clínicos não têm sido realizados com óleo de arroz com alto teor de gama-orizanol (ORTHOEFER, 2005).

A figura 2 compara o teor de gama-orizanol presente no óleo de arroz bruto em relação aos processamentos alcalino e físico.

Figura 2 - Teor de gama-orizanol de acordo com o tipo de refino

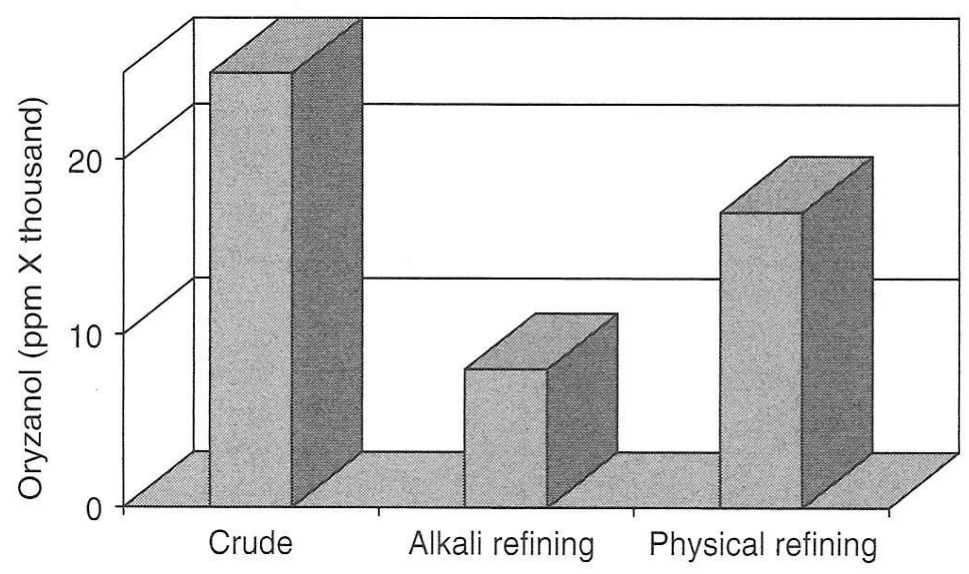

Fonte: (ORTHOEFER, 2005)

Devido à sua estabilidade em condições de armazenamento e cocção, além das potenciais aplicações na saúde, o óleo de farelo de arroz é muito popular em vários países asiáticos, onde cerca de 1,3 milhão de toneladas foram produzidas em 2006 (PESTANA et al., 
2008). Segundo a FAO (2013), Índia, China, Mianmar, Indonésia e Vietnam foram os maiores produtores mundiais do óleo de farelo de arroz em 2012.

Segundo Wheeler e Garleb (1991), as semelhanças estruturais entre gama-orizanol, fitoesteróis e colesterol levaram a inúmeras teorias e alegações sobre os efeitos fisiológicos, metabólicos e o desempenho destes compostos após a ingestão. A base fitoesterol dos ésteres de ácido ferúlico é estruturalmente semelhante ao colesterol, com as diferenças que ocorrem principalmente na cadeia lateral, por exemplo, o campesterol tem um grupo metil extra no C24 , enquanto que o $\beta$-sitosterol e o estigmasterol têm um grupo etil adicional no C-24. O ßsitosterol, um dos componentes do gama-orizanol, possui estrutura química que poderia ser prontamente convertida em andrógenos, de forma anabólica (Figura 3).

Figura 3 - Estrutura química do colesterol e fitosteróis
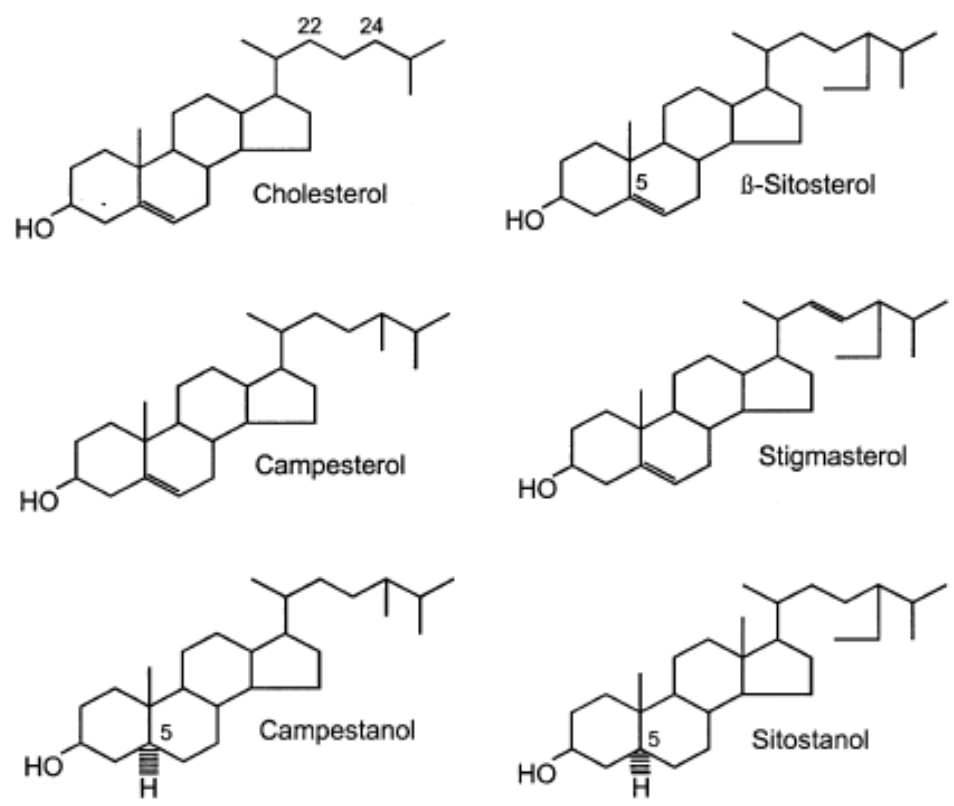

Fonte: (MOGHADASIAN et al., 2000)

Nos vegetais, os fitoesteróis desempenham funções equivalentes às do colesterol nos animais, sendo assim necessários como componentes das membranas celulares e precursores de biomoléculas importantes, incluindo hormônios sexuais e vitaminas (LERMA-GARCIA et al., 2009). 
A atividade anabólica da testosterona e de seus derivados é primeiramente manifestada na ação miotrófica, que resulta em maior massa e força muscular (AMBAR, 2008). Bhasin et al. (2001) demonstraram que variações na concentração plasmática de testosterona, induzidas pela administração combinada de GnRH-agonista com doses graduais de testosterona, estão relacionadas com alterações no tamanho muscular e na quantidade de gordura. Segundo Herbst e Bhasin (2004), os valores das mudanças induzidas na massa gorda e na massa magra estão correlacionados com a dosagem e concentração de testosterona, modulando os receptores de androgênios e inibindo a formação de células adiposas.

Segundo Zhao e Moghadasian (2008), os esteróis do ácido ferúlico, como o gamaorizanol podem ser absorvidos por mecanismos de difusão passiva, devido ao seu alto coeficiente de partição óleo-água. Nesse sentido, Fujiwara et al. (1983) reportaram que a maior parte do gama-orizanol absorvido (marcado com carbono 14) pode ser recuperado intacto na veia mesentérica, sugerindo mecanismo de difusão passiva envolvido no transporte do gama-orizanol através da mucosa intestinal.

Nanua et al. (2000) obtiveram efeito significativo com uso de gama-orizanol na concentração de $0,1 \%$ com o intuito de retardar a oxidação do leite em pó integral sem afetar suas características sensoriais, confirmando a atividade antioxidante desta substância.

\subsection{Estudos com gama-orizanol em humanos}

Estudos clínicos demonstraram que a administração oral de gama-orizanol pode ser eficaz no tratamento de diferentes distúrbios gastrointestinais, incluindo gastrite, úlceras gástricas e duodenais induzidas pelo estresse sugerindo que a proteção de mucosa gastrointestinal pode ser devido à potente atividade antioxidante do gama-orizanol e que este atue sobre o sistema nervoso autônomo normalizando a estimulação vagal de secreção de gastrina (INOVE ${ }^{1}$ et al.,1976 apud ACKERSON, 1997, p. 277; KIMURA ${ }^{2}$ et al., 1977 apud

\footnotetext{
${ }^{1}$ INOVE, T., et al. Therapeutic effectiveness of gamma-oryzanol on chronic gastritis, Shinyaku to Rinsho, v. 25 , n. 5, p. 3, 1976.

${ }^{2}$ KIMURA, I., et al. Clinical evaluation of gamma-oryzanol on peptic ulcers, Shinyaku to Rinsho, v. 26, n. 3, p. 3, 1977.
} 
ACKERSON, 1997, p. 277; OKADA; YAMAGUCHI ${ }^{3}, 1983$ apud ACKERSON, 1997, p. 278).

Fry et al. (1997) testaram a efetividade da suplementação oral (500 mg/dia) de gamaorizanol em homens fisiculturistas. Nenhuma diferença significativa foi observada na concentração de hormônios circulantes (testosterona, cortisol, estradiol, GH, insulina, betaendorfina), minerais (cálcio e magnésio), albumina ou lipídeos sanguíneos. Os resultados demonstraram que a suplementação oral de $500 \mathrm{mg} / \mathrm{kg}$ de gama-orizanol durante nove semanas não interferiu no desempenho físico ou nos parâmetros fisiológicos relatados.

Outras pesquisas sugerem que o gama-orizanol poderia aumentar a liberação de endorfina e auxiliar o desenvolvimento muscular, estimulando a utilização do gama-orizanol como suplemento esportivo (BONNER et al., 1990; BUCCI et al., 1990).

Talbott (2002) descreve a possível teoria sobre a suplementação com gama-orizanol, e que esta estaria relacionada com o efeito exercido sobre o sistema hormonal especificamente na habilidade em elevar a concentração de testosterona, onde o gamaorizanol poderia estimular o hipotálamo a secretar GnRH, que por sua vez, estimularia a liberação de $\mathrm{GH}$, e assim através da testosterona e do GH obter efeitos ergogênicos. Contrariamente, Geor (2006) relata não existirem evidências em nenhuma espécie que a suplementação com gama-orizanol aumente a massa ou força muscular, ou qualquer outro aspecto de desempenho físico, embora existam vários produtos com esta substância sendo utilizados no mercado esportivo.

Suh et al. (2007), reportam alívio de desordens metabólicas ocasionadas pela menopausa, aceleração do crescimento e estímulo de glândulas sexuais de animais através do uso dessa substância.

2.3 Estudos com gama-orizanol em roedores

Tamagawa et al. (1992a,b) demonstraram in vivo a não-toxicidade e nãocarcinogenicidade do gama-orizanol em ratos e cobaias. Nestes estudos, grupos de 50 machos

${ }^{3}$ OKADA, T.; YAMAGUCHI, N. Antioxidative effect and pharmacology of oryzanol. Journal of Japanese Oil Chemistry Society, v. 32, n. 6, p. 305, 1983. 
e 50 fêmeas foram submetidos a uma dieta contendo zero (controle), 200, 600 ou $2000 \mathrm{mg}$ de gama-orizanol (kg/peso vivo/dia) durante 78 semanas (cobaias) ou dois anos (ratos) e em nenhum dos tratamentos houveram mudanças significativas na hematologia, peso dos órgãos, condição geral, peso corporal, consumo alimentar, mortalidade, ou incidência tumoral.

Estudo proposto por Ieiri et al. (1982) verificou que uma simples injeção subcutânea de $20 \mathrm{mg} / \mathrm{kg}$ de gama-orizanol suprimiu a síntese do GH e liberação de prolactina uma hora após sua administração. O gama-orizanol aumentou significantemente a liberação de norepinefrina pelo núcleo hipotalâmico central, explicando as variações nos níveis plasmáticos de GH e prolactina, sugerindo que este componente do óleo de arroz pode afetar a síntese e/ou a liberação de pelo menos dois neurotransmissores hipotalâmicos, a dopamina e a norepinefrina.

A nutrição e o estado nutricional podem ter profundos efeitos na função imunológica. Neste sentido, certos nutrientes podem regular a função imune e tanto a deficiência ou o excesso destes pode afetar adversamente o número e a atividade das células do sistema imunológico. Sierra et al. (2005) estudaram o efeito do óleo de arroz sobre a resposta imune de camundongos. Utilizando como controle o óleo de girassol, foi demonstrado que linfócitos $\mathrm{B}$ e $\mathrm{T}$ tiveram significativo aumento no tratamento com dieta à base de óleo de arroz, onde também foi demonstrado aumento na resposta imune dos macrófagos.

Ohara et al. (2009), demonstraram que a administração oral de gama--orizanol melhora a absorção e as concentrações séricas de adiponectina em camundongos, podendo impedir ou melhorar o diabetes tipo 2 e as síndromes metabólicas relacionadas, como a resistência insulínica.

\subsection{Estudos com gama-orizanol em frangos}

Anitha et al. (2007), adicionou óleo de farelo de arroz bruto na dieta de frangos de corte, mas não observou diferença nos níveis séricos de colesterol total, HDL-C, LDL-C e triglicérides entre os grupos de tratamento. Todos os parâmetros bioquímicos séricos diminuíram linearmente, com redução proporcional nos valores do colesterol total, quando o nível de inclusão do óleo de farelo de arroz bruto foi aumentado de 1 a 5\%. Os parâmetros bioquímicos séricos em todos os grupos de tratamento foram menores em relação ao controle. Tal observação foi consistente com Fan et al. (1996), que relataram que os níveis séricos de triglicérides e LDL-C são reduzidos nos pintos em crescimento recebendo óleo de farelo de 
arroz na dieta. Trabalhando com frangos de corte, Murugesan (1997) observou aumento significativo no ganho de peso quando $2 \%$ de óleo de farelo de arroz bruto foram adicionados à ração.

\subsection{Estudos com gama-orizanol em equinos}

O primeiro estudo em equinos foi realizado por Frank et al. (1995), onde avaliaram a composição de triglicérides e lipoproteínas plasmáticas, além da dinâmica glicêmica de oito éguas da raça Quarto de Milha, com peso médio de $429 \mathrm{~kg}$ e idade variando entre 5 a 17 anos. À dieta dos animais, de acordo com o tratamento, foi adicionado água, óleo de milho, óleo de farelo de arroz refinado, ou óleo de farelo de arroz bruto. A concentração de triglicérides plasmática foi numericamente menor no grupo recebendo óleo de farelo de arroz bruto (que contém gama-orizanol em maior quantidade), porém não foram observados os efeitos hipocolesterêmicos citados em outras espécies.

$\mathrm{Na}$ área da reprodução, Arlas et al. (2008) utilizaram quatro garanhões, com idade variando de seis a trinta anos de idade, suplementados com óleo de arroz semi-refinado contendo $1 \%$ de gama-orizanol, durante 80 dias. Não foi observada alteração significativa em termos de volume, integridade da membrana, concentração plasmática de testosterona ou estradiol, porém aumentou a capacidade antioxidante total do sêmen. Além disso, a funcionalidade da membrana superior e da motilidade foi melhorada. Da mesma forma, Gonzaga et al. (2012), suplementando a dieta de garanhões com óleo de arroz semi-refinado com alto teor de gama-orizanol durante 60 dias, não observaram diferença entre os tratamentos para as variáveis volume, motilidade, concentração espermática e defeitos totais, porém obtiveram aumento na concentração de colesterol total e LDL-C plasmáticos para os animais suplementados com óleo de arroz.

Oliveira et al. (2010) trabalharam com 14 equinos, machos, com idade entre 3 a 14 anos e avaliaram o peso e perfil hematológico de equinos suplementados, ou não, com óleo de arroz semi-refinado com alto teor de gama-orizanol na dieta de equinos $(0,5 \mathrm{~mL} / \mathrm{kg} / \mathrm{peso}$ corporal), e concluíram que este foi determinante para impedir o aumento de lactato, mas não encontraram diferença em relação ao peso corporal e proteína total.

Wandembruck et al. (2010) utilizaram doze equinos, machos e fêmeas, submetidos a exercícios diários em redondel, e suplementados com óleo de arroz contendo gama-orizanol 
em diferentes quantidades (120, 240,360, 480 e $600 \mathrm{~mL} / \mathrm{animal} / \mathrm{dia})$ comprovaram que os equinos se mantiveram em adequado metabolismo energético, através da avaliação dos valores plasmáticos das enzimas CK, AST e LDH e de glicose.

Em recente estudo, Ostaszewski et al. (2012) trabalharam com suplementação de gama-orizanol (GO) e ß-hidroxi- $\beta$-metilbutirato (HMB) em animais da raça Puro Sangue Inglês. Foram utilizados 24 animais, 12 machos e 12 fêmeas, com idade entre três e seis anos, com peso médio de $520 \mathrm{~kg}$, onde avaliaram a frequência cardíaca, hematócrito, enzimas musculares, lactato e glicose. O grupo controle consumiu $150 \mathrm{~g}$ de matriz peletizada sem $\mathrm{HMB}$, e $20 \mathrm{~mL}$ de óleo vegetal, o grupo gama-orizanol consumiu $150 \mathrm{~g}$ de matriz peletizada sem $\mathrm{HMB}+3 \mathrm{~g}$ de GO suspenso em $20 \mathrm{~mL}$ de óleo de farelo de arroz, o grupo HMB consumiu $150 \mathrm{~g}$ de suplemento granulado de HMB e $20 \mathrm{~mL}$ de óleo de vegetal, e o grupo GO+HMB consumiu $150 \mathrm{~g}$ de suplemento granulado de HMB e 3 g de GO suspenso em 20 $\mathrm{ml}$ de óleo de farelo de arroz. Os resultados demonstraram que a suplementação com gamaorizanol em animais da raça Puro Sangue Inglês pode reduzir lesões musculares e melhorar a recuperação do treinamento, aumentando os resultados de desempenho. Este trabalho, até o momento, é o único disponibilizado em várias bases de dados que utilizaram gama-orizanol puro, na forma de pó cristalino. 


\section{REFERÊNCIAS}

AMBAR, G. Efeitos da administração prolongada do esteroide anabolizante decanoato de nandrolona em comportamentos emocionais e na expressão de genes relacionados ao sistema serotoninérgico em diferentes áreas cerebrais de camundongos. 2008. $80 \mathrm{f}$. Dissertação (Mestrado em Ciências) - Faculdade de Medicina da Universidade de São Paulo, São Paulo, 2008.

ANITHA, B.; MOORTHY, M.; VISWANATHAN, K. Muscle Cholesterol and Serum Biochemical Changes in Broilers Fed with Crude Rice Bran Oil. International Journal of Poultry Science, v. 6, n. 12, p. 855-857, 2007.

ARLAS, T. R.; PEDERZOLLI, C. D.; TERRACIANO, P. B.; TREIN, C. R.; BUSTAMANTE-FILHO, I. C.; CASTRO, F. S.; MATTOS, R. C. Sperm quality is improved feeding stallions with a rice oil supplement. Animal Reproduction Science, v. 107, n. 3-4, p. 206, 2008.

BHASIN, S.; WOODHOUSE, L.; CASABURI, R.; SINGH, A.B.; BHASIN, D.; BERMAN, N.; CHEN, X.; YARASHESKI, K. E. ; MAGLIANO, L.; DZEKOV, C.; DZEKOV, J.; BROSS, R.; PHILLIPS, J.; SINHA-HIKIM, I;. SHEN, R.; STORER, T.W. Testosterone dose-response relationships in healthy young men. American Journal Physiology - Endocrinology and Metabolism, v. 281, p. E1172-E1181, 2001.

BONNER, B.; WARREN, B.; BUCCI, L. Influence of ferulate supplementation on post exercise stress hormone levels after repeated exercise stress. Journal of Applied Sports Science Research, v. 4, p.10, 1990.

BUCCI, L.R.; BLACKMAN, G.; DEFOYD, W.; KAUFMANN, R.; MANDEL-TAYES, C.; SPARKS, W.S.; STILES, J.C.;HICKSON, J.F. Effect of ferulate on strength and body composition of weightlifters. Journal of Applied Sports Science Research, v.7, p.107,1990.

FAO (2013) Rice bran oil world production. FAOSTAT.

http://faostat3.fao.org/home/index.html\#DOWNLOAD. Acesso em: 12 de Setembro de 2013.

FAN, Q.; FENG, J.; WU, S.; SPECHT, K.; SHE, S. Nutritional evaluation of rice bran oil and a blend with corn oil. Poultry Abstracts, v. 22, p. 3118, 1996.

FRANK, N.; ANDREWS, F. M.; ELLIOTT, S. B.; LEW, J.; BOSTON, R.C. Effects of rice bran oil on plasma lipid concentrations, lipoprotein composition, and glucose dynamics in mares. Journal of Animal Science, v. 83, p. 2509-2518, 2005.

FRY, A. C.; BONNER, E.; LEWIS, D. L.; JOHNSON, R. L.; STONE, M. H.; KRAEMER, W. J. The effects of gamma-oryzanol supplementation during resistance exercise training. International Journal of Sport Nutrition, v. 7, p. 318-329, 1997.

FUJIWARA, S.; SAKURAI, S.; SUGIMOTO, I.; AWATA, N. Absorption and metabolism of gamma-oryzanol in rats. Chemical \& Pharmaceutical Bulletin, v. 31, p. 645-652, 1983. 
GEOR, R. J. The role of nutritional supplements and feeding strategies in equine athletic performance. Equine and Comparative Exercise Physiology, v. 3, n. 3, p. 109-119, 2006.

GONZAGA, I. V. F.; TAMAS, W. T.; ETCHICHURY, M.; GOBESSO, A. A. O. Qualidade espermática e perfil plasmático de lipídeos em garanhões suplementados com óleo de arroz semirrefinado com alto teor de gama-orizanol. Brazilian Journal Veterinary Research and Animal Science, v. 49, n. 3, p. 215-220, 2012.

HERBST, K. L.; BHASIN, S. Testosterone action on skeletal muscle. Current Opinion Clinical Nutrition Metabolic Care, v. 7, n. 3, p. 271-277, 2004.

IEIRI, T.; KASE N.; HASHIGAMI, Y.; KOBORI, H.; NAKAMURA, T.; SHIMODA, S. Effects of gamma-oryzanol on the hypothalamo-pituitary axia in the rat. Nippon Naibunpi Gakkai Zasshi, v. 20, n. 58, p. 1350-1356, 1982.

JULIANO, C.; COSSU, M.; ALAMANNI, M. C.; PIU, L. Antioxidant activity of gammaoryzanol: Mechanism of action and its effect on oxidative stability of pharmaceutical oils. International Journal of Pharmaceutics, v. 299, p. 146-154, 2005.

LERMA-GARCÍA, M. J.; HERRERO-MARTÍNEZ, J. M.; SIMÓ-ALFONSO, E. F.; MENDONÇA, C. R. B.; RAMIS-RAMOS, G. Composition, industrial processing and applications of rice bran $\gamma$-oryzanol. Food Chemistry, v. 115, p. 389-404, 2009.

LICHENSTEIN, A. H.; AUSMAN, L. M.; CARRASCO, W.; GUALTIERI, L. J.; JENNER, J. L.; ORDOVAS, J. M.; NICOLOSI, R. J.; GOLDIN, B. R.; SCHAEFER, E. J. Rice bran oil consumption and plasma lipid levels in moderately hypercholesterolemic humans.

Arteriosclerosis and Thrombosis, v. 14, p. 549-556, 1994.

LIMA, R. A. S.; SHIROTA, R.; BARROS, G. S. C. Estudo do complexo do agronegócio cavalo. Piracicaba: ESALQ/USP, 2006. 250 p.

MICHAELIS. Dicionário de Português on line Michaelis. Disponível em: $<$ http://michaelis.uol.com.br/moderno/portugues/index.php?lingua=portuguesportugues\&palavra=ergog\%EAnico > Acesso em: 02 nov. 2013.

MOGHADASIAN, M. H. Pharmacological properties of plant sterols in vivo and in vitro observations. Life Sciences, v. 67, p. 605-615, 2000.

MORETTO, E.; FETT, R. Tecnologia de óleos e gorduras vegetais na indústria de alimentos. São Paulo: Livraria Varela, 1998.

MURUGESAN, V. Utilization of soapstock as an energy source in broiler ration. 1997. 98 p. (Tese) - Tamil Nadu Veterinary and Animal Sciences University, Chennai, 1997.

NANUA, J. N.; MCGREGOR, J. U.; GODBER, J. S. Influence of high-oryzanol Rice Bran Oil on the Oxidative Stability of Whole Milk Powder. Journal of Dairy Science, v. 83, p. 2426-2431, 2000. 
NARAYAN, A. V.; BARHATE, R. S.; RAGHAVARAO, M. S. Extraction and purification of oryzanol from rice bran oil and rice bran oil soapstock. Journal of American Oil Chemistry Society, v. 83, n. 8, p. 663-670, 2006.

OHARA, K.; UCHIDA, A.; NAGASAKA, R.; USHIO, H.; OHSHIMA, T. The effects of hydroxy cinnamic acid derivatives on adiponectin secretion, Phytomedicine, v. 16, p. 130 137, 2009.

OLIVEIRA, R. N.; MARQUES JR., A. P.; XAVIER, P. R.; ALVES, G. E. S; PAES, P. R. O.; GOBESSO, A. A. O. Avaliação hematológica e bioquímica de equinos suplementados com óleo de arroz semi-refinado, rico em gama-orizanol. Arquivo Brasileiro de Medicina Veterinária e Zootecnia, v. 62, n. 5, p. 1043-1047, 2010.

ORTHOEFER, F. T. Rice bran oil. In: SHAHIDI, F. Bailey's industrial oil and fat products. Jersey: John Wiley \& Sons New, 2005. v. 2, cap. 10, p. 482-488.

OSTASZEWSKI, P.; KOWALSKA, A.; SZARSKA, E.; SZPOTANSKI, P.; CYWINSKA, A.; BALASINSKA, B; SADKOWSKI, T. Effects of ß-Hydroxy-ß-Methylbutyrate and gOryzanol on Blood Biochemical Markers in Exercising Thoroughbred Race Horses. Journal of Equine Veterinary Science, v. 32, p. 542-551, 2012.

PESTANA, V. R.; ZAMBIAZI, R. C.; MENDONÇA, C. R. B.; BRUSCATTO, M. H.; LERMA-GARCÍA, M. J.; RAMIS-RAMOS, G. Quality Changes and Tocopherols and $\gamma$ Orizanol Concentrations in Rice Bran Oil During the Refining Process. Journal of American Oil Chemistry Society, v. 85, p. 1013-1019, 2008.

ROGERS, E. J.; RICE, S. M.; NICOLOSI, R. J.; CARPENTER, D. R.; MUCLELLAND, C. A.; ROMANCZYK, L. J. Identification and Quantitation of $\gamma$-Oryzanol components and simultaneous assessment of tocols in rice bran oil. Journal of American Oil Chemistry Society, v. 70, p. 301-307, 1993.

RONG, N.; AUSMAN, L. M.; NICOLOSI, R. J. Oryzanol decreases cholesterol absorption and aortic fatty streaks in hamsters. Lipids, v. 32, n. 3, p. 303-308, 1997.

SCAVARIELLO, E. M.; ARELLANO, D. B. $\gamma$-Oryzanol: un importante componente del aceite de salvado de arroz. Archivos Latinoamericanos de Nutrición, v. 48, p. 7-12, 1998.

SEETHARAMAIAH, G. S.; KRISHNAKANTHA, T. P.; CHANDRASEKHARA, N. Influence of oryzanol on platelet aggregation in rats. Journal of Nutrition Science and Vitaminology, v. 36, p. 291-297, 1990.

SIERRA, S.; LARA-VILLOSLADA, F.; OLIVARES, M.; JIMÉNEZ, BOZA, J.; XAUS, J. Increased immune response in mice consuming rice bran oil. European Journal of Nutrition, v. 44, p. 509-516, 2005.

SUH, M.; YOO, S.; LEE, H. G. Antioxidative activity and structural stability of microencapsulated gamma-oryzanol in heat-treated lards. Food Chemistry, v.100, p. 10651070, 2007. 
TALBOTT, S. M. A guide to understanding dietary supplements. Binghamton: The Haworth Press, 2002. cap. 5, p. 152-155.

TAMAGAWA, M.; OTAKI, Y.; TAKAHASHI, T.; OTAKA, T.; KIMURA, S.; MIWA, T. Carcinogenicity study of gamma-oryzanol in B6C3F1 mice. Food and Chemical Toxicology. v. 30, n.1, p. 49-56, 1992a.

TAMAGAWA, M.; SHIMIZU, Y.; TAKAHASHI, T.; OTAKA, T.; KIMURA, S.; KADOWAKI, H.; UDA, F.; MIWA, T. Carcinogenicity study of gamma-oryzanol in F344 rats. Food and Chemical Toxicology, v. 30, p. 41-48, 1992b.

XU, Z.; GODBER, J. S. Purification and identification of components of $\gamma$-oryzanol in rice bran oil. Journal of Agricultural and Food Chemistry, v. 47, p. 2724-2728, 1999.

ZHAO, Z.; MOGHADASIAN M. H. Chemistry, natural sources, dietary intake and pharmacokinetic properties of ferulic acid: A review. Food Chemistry, v. 109, p. 691-702, 2008.

WANDEMBRUCK, K. T.; SONCIN, M. R. S. P.; GARCIA, H. A. C.; TORRECILHAS, J. A.; POLIZEL, V. P.; FURTADO, C. E. Efeito da inclusão de óleo de arroz em dietas para equinos através da determinação enzimática e de glicose. In: Anais da $6^{\text {a }}{ }^{\text {REUNIÃO }}$ ANUAL DA SOCIEDADE BRASILEIRA PARA O PROGRESSO DA CIÊNCIA, 63., 2011, Goiânia. Anais... 2011. E.6.2.

WHEELER, K. B.; GARLEB, K. A. Gamma-Oryzanol - Plant Sterol Supplementation: Metabolic, Endocrine, and Physiologic Effects. International Journal of Sport Nutrition, v. 1, p. 170-177, 1991. 
CAPÍTULO I

EFEITO DA SUPLEMENTAÇÃO COM GAMA-ORIZANOL SOBRE O DESEMPENHO DE EQUINOS SUBMETIDOS AO EXERCÍCIO AERÓBIO 


\section{RESUMO}

Com o objetivo de avaliar o efeito da suplementação com gama-orizanol em equinos submetidos a exercício aeróbio foram utilizados dez cavalos da raça Puro Sangue Árabe, machos, castrados, com idade média de $35 \pm 8,15$ meses e peso corporal médio de $375 \pm 22,78$ $\mathrm{kg}$ no início do período experimental, divididos em dois lotes de cinco animais cada, denominados grupos "controle" e "gama". O experimento foi conduzido no Laboratório de Pesquisa em Alimentação e Fisiologia do Exercício de Equinos (LABEQUI), pertencente à FMVZ-USP, no Campus Administrativo de Pirassununga, São Paulo, adotando-se o consumo diário individual de $2 \%$ do peso corpóreo, com base na matéria seca, sendo $50 \%$ de volumoso composto por feno de gramínea e 50\% de concentrado comercial. Em cada refeição, todos os animais receberam $50 \mathrm{~mL}$ de óleo vegetal, sendo que apenas o grupo gama recebeu o gamaorizanol (dez gramas diárias). Ambos os grupos foram exercitados em caminhador eletrônico, durante 60 minutos, na velocidade máxima de $12 \mathrm{~km} / \mathrm{h}$, cinco vezes por semana. Durante o período experimental de seis meses, os cavalos foram mensalmente avaliados quanto ao ganho de peso, escore de condição corporal, e lipídeos plasmáticos (colesterol total e frações HDL-C, VLDL-C, LDL-C, e triglicérides). A cada quarenta e cinco dias foram realizadas mensurações ultrasonográficas da espessura da camada muscular e adiposa do músculo Longissimus dorsi, e da espessura da camada de gordura na região de inserção da cauda. Foi utilizado o delineamento inteiramente casualizado com medidas repetidas no tempo. Em relação ao peso corporal ou as medidas ultrassonográficas não foi observada diferença entre os grupos, porém foi verificada redução do escore corporal, com redução ao longo do tempo $(\mathrm{p}=0,04)$ de $10 \%$ para o grupo gama quando comparado com o grupo controle $(6,5 \%)$. A concentração de colesterol total foi maior $(\mathrm{p}=0,001)$ para o grupo gama $(113,99 \mathrm{mg} / \mathrm{dL})$ do que o grupo controle $(108,55 \mathrm{mg} / \mathrm{dL})$. A suplementação com gama-orizanol de equinos submetidos a exercício aeróbio pode proporcionar redução do escore de condição corporal e elevar a concentração de colesterol plasmático.

Palavras-chave: Cavalos. Colesterol. Escore corporal. Gama-orizanol. Triglicérides. 


\begin{abstract}
In order to evaluate the effect of supplementation with gamma-oryzanol in horses undergoing aerobic exercise were used ten Purebred Arabian horses, geldings, mean age 35 \pm 8.15 months and mean weight of $375 \pm 22.78 \mathrm{~kg}$ at the beginning of the experimental period, divided into two groups of five animals each, named "gama" and "control" groups. The experiment was conducted at the Laboratório de Pesquisa em Alimentação e Fisiologia do Exercício de Equinos (LABEQUI), belonging to FMVZ-USP, at Campus Administrativo de Pirassununga, São Paulo, adopting individual daily consumption of $2 \%$ of body weight, based on dry matter, $50 \%$ of forage composed of grass hay and 50\% commercial concentrate. In each meal, the animals received $50 \mathrm{~mL}$ of vegetable oil, and only the group "gama" received the gammaoryzanol (ten grams daily). Both groups were trained in electronic walker for 60 minutes at a maximum speed of $12 \mathrm{~km} / \mathrm{h}$, five times a week. During the trial period of six months, the horses were evaluated monthly to weight gain, body condition score, and plasma lipids (total cholesterol and HDL-C, VLDL-C, LDL-C, and triglycerides). The every forty-fifth days were performed ultrasonographic measurements of the thickness of muscle and adipose Longissimus dorsi, and the thickness of the fat layer at the insertion of the tail. We used a completely randomized design with repeated measures. In relation to body weight or measures ultrasound there was no difference between the groups, but the reduction was observed body condition, reducing over time $(\mathrm{p}=0.04)$ of $10 \%$ for the range when compared with the control group $(6.5 \%)$. The total cholesterol concentration was higher $(\mathrm{p}=0.001)$ for the gama group $(113.99 \mathrm{mg} / \mathrm{dL})$ than the control group $(108.55 \mathrm{mg} / \mathrm{dL})$. Supplementation with gamma- oryzanol in horses undergoing aerobic exercise can provide a reduction of body condition score, and can raise the concentration of plasma cholesterol.
\end{abstract}

Keywords: Body score. Cholesterol. Gamma-oryzanol. Horses. Triglycerides. 


\section{INTRODUÇÃO}

As respostas induzidas pelo treinamento relacionadas com a capacidade de trabalho físico parecem ser semelhantes em atletas equinos e humanos (DE GRAAF-ROELFSEMA et al., 2007). O treinamento de resistência, como o treinamento para a modalidade de enduro, promove numerosas adaptações musculares, incluindo o aumento da capacidade oxidativa da fibra muscular e transições fenotípicas, levando a alterações metabólicas e estruturais (SEENE et al., 2005). Esta adaptação ao treinamento ocorre em forma contínua baseada na intensidade e duração do exercício (RIVERO et al., 2007).

Estas alterações que ocorrem no organismo durante o exercício estão diretamente relacionadas ao tipo de esforço físico realizado. Para os cavalos de enduro, onde as distâncias podem chegar a $160 \mathrm{~km} / \mathrm{h}$ em um dia, geralmente na média de $16-18 \mathrm{~km} / \mathrm{h}$, dependendo da superfície do solo, a energia utilizada é gerada aerobiamente em um percentual acima de $94 \%$ (BOFFI, 2008).

Os testes de avaliação física em equinos atletas podem ser conduzidos a campo ou em laboratórios, com auxílio de equipamentos. Nos testes a campo, as condições do ambiente estão próximas às encontradas nas competições, como corrente de ar, superfície de solo e impacto do cavaleiro; por outro lado, não há como padronizar os testes nestas condições (EVANS, 2008). O uso do exercitador circular, apesar do menor gasto calórico proporcionado, em alguns aspectos fisiológicos, hematológicos e bioquímicos, produz efeitos no organismo semelhantes ao teste a campo, podendo ser considerado como meio alternativo de treinamento e avaliação de equinos em fase inicial de treinamento, com economia de tempo e mão de obra (PINTO, 2010).

No segmento de cavalos de esporte, aumenta a cada dia a comercialização de suplementos nutricionais como, por exemplo, o gama-orizanol. Seja na forma de compostos líquidos, concentrados contendo farelo de arroz, óleo de farelo de arroz bruto ou semi refinado, ou ainda na composição de "bisnagas energéticas" para administração oral. Porém, contrariamente aos estudos realizados em outras espécies, pouco se conhece sobre as ações do gama-orizanol no organismo equino.

O objetivo desde estudo foi verificar o efeito da suplementação com gama-orizanol para equinos submetidos a exercício aeróbio, avaliando o ganho de peso, escore de condição corporal, concentração de lipídeos plasmáticos (colesterol total e frações HDL-C, LDL-C e 
VLDL-C, e triglicérides) assim como as medidas ultrassonográficas de músculo e gordura das regiões lombar e caudal.

\subsection{MATERIAIS E MÉTODOS}

Todos os procedimentos utilizados neste estudo foram submetidos à avaliação do comitê de ética em experimentação animal da Faculdade de Medicina Veterinária e Zootecnia da Universidade de São Paulo, estando registrado sob o protocolo de número 1794/2009.

O experimento foi conduzido no Laboratório de Pesquisa em Alimentação e Fisiologia do Exercício em Equinos (LABEQUI), pertencente à Faculdade de Medicina Veterinária e Zootecnia da Universidade de São Paulo, situado no Campus Administrativo de Pirassununga, Estado de São Paulo, onde foram utilizados dez equinos da raça Puro Sangue Árabe, machos, castrados, hígidos, com idade média de $35 \pm 8,15$ meses e peso corporal médio de $375 \pm 22,78$ $\mathrm{kg}$ ao início do período experimental, alojados em piquetes.

Foi adotado o consumo diário individual de $2 \%$ do peso corporal, em matéria seca, sendo $50 \%$ concentrado e $50 \%$ volumoso, divididos em duas refeições diárias. O concentrado foi fornecido em comedouros individuais, em área de serviço, no sistema tipo "lanchonete", enquanto que o volumoso foi distribuído em manjedouras no piquete. As dietas foram compostas por feno de gramínea Cynodon sp, variedade Tifton 85 e concentrado comercial, além de sal mineralizado e água ad libitum, seguindo as recomendações estabelecidas no Nutrient Requeriments of Horses - NRC (2007) para equinos nesta categoria.

Foram compostos dois grupos de tratamento com cinco cavalos cada, sendo um grupo denominado "controle" e o outro "gama". O grupo gama recebeu cinco gramas de gamaorizanol puro, apresentado na forma de pó cristalino, e dissolvido em $50 \mathrm{~mL}$ de óleo vegetal, por refeição, sendo adicionado ao concentrado diretamente no comedouro. A inclusão de óleo vegetal se faz necessária devido à melhor biodisponibilidade do gama-orizanol em meio lipídico, como demonstrado por Gillespie (2003).

Todos os animais foram exercitados cinco vezes por semana, durante sessenta minutos, na velocidade máxima de $12 \mathrm{~km} / \mathrm{h}$, em exercitador circular mecânico para cavalos (Equiboard $^{\circledR}$ ), controlado eletronicamente. O protocolo de exercício foi dividido em seis estágios: (1 $\left.{ }^{\circ}\right) 10$ minutos na velocidade de $7 \mathrm{~km} / \mathrm{h} ;\left(^{\circ}\right) 15$ minutos na velocidade de $10 \mathrm{~km} / \mathrm{h}$;

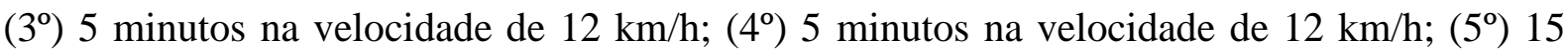


minutos na velocidade de $10 \mathrm{~km} / \mathrm{h} ;\left(6^{\circ}\right) 10$ minutos na velocidade de $7 \mathrm{~km} / \mathrm{h}$. Entre os estágios 3 e 4 ocorria a inversão de sentido do exercitador.

Mensalmente todos os animais foram pesados em balança digital (Toledo ${ }^{\circledR}$ modelo MGR-3000 Júnior) e avaliados em relação ao escore de condição corporal (ECC) de acordo com o modelo proposto por Henneke et al. (1983), o qual classifica os animais em escala de um a nove, dependendo da quantidade de gordura depositada em seis áreas específicas do corpo: pescoço, espádua, costelas, coluna, lombo e garupa; sendo o grau um para animais extremamente magros, e o grau nove para aqueles extremamente obesos.

Com a finalidade de avaliar o efeito do exercício aeróbio e a suplementação com gama-orizanol sobre o acúmulo de gordura e desenvolvimento muscular, foram realizadas mensurações ultrasonográficas a cada 45 dias do período experimental (D0, D45, D90, D135 e D180) referentes à: espessura da camada de gordura (EGL) e da camada muscular (EML) no corte transversal do músculo longissimus dorsi, entre a $17^{\mathrm{a}}$ e a $18^{\mathrm{a}}$ costela; e espessura da camada de gordura na região de inserção da cauda a $5 \mathrm{~cm}$ lateral ao eixo da coluna vertebral e $7 \mathrm{~cm}$ cranial a base da cauda (EGC). Foi utilizado aparelho de ultrassom (Pie-Medical ${ }^{\circledR}$, modelo Falco 100), com transdutor linear de $5 \mathrm{Mhz}$, seguindo metodologia adotada por Martins (2011).

Para determinação de triglicérides, colesterol total e suas frações (HDL-C, LDL-C e VLDL-C), foram colhidas amostras sanguíneas mensais do dia 0 ao dia 180 , de todos os animais, através de punção da veia jugular utilizando agulhas 25 x 0,8 mm e tubos em sistema a vácuo (Becton-Dickinson ${ }^{\circledR}$ ) com heparina sódica. As análises foram realizadas através de método enzimático colorimétrico utilizando kits comerciais $\left(\right.$ Laborlab $^{\circledR}$ ) e leitura realizada em analisador automático de bioquímica sanguínea $\left(\mathrm{SBA}_{200-C E L M}{ }^{\circledR}\right)$, segundo método de Lowry (1977).

O delineamento experimental utilizado foi inteiramente casualizado com medidas repetidas no tempo, com dois tratamentos, e cinco repetições por tratamento. Os dados foram analisados utilizando o procedimento PROC MIXED (Versão 9.2, SAS Institute, Cary, NC 2010) após verificação da normalidade dos resíduos pelo teste de Shapiro-Wilk (PROC UNIVARIATE). Foi utilizado o efeito aleatório animal dentro dos tratamentos. O método de Kenward-Rogers foi usado para calcular os graus de liberdade do denominador do teste F. As análises foram realizadas como medidas repetidas no tempo considerando como efeito fixo o tempo (D0, D30, D60...), tratamento (com ou sem suplementação), e interação (tempo*tratamento). Para as análises ao longo do tempo, os tratamentos foram confrontados dentro de cada tempo através da opção PDIFF (Perceptual Diff) com as médias ajustadas 
obtidas por meio do LSMEANS (Least Squares Means). Para as variáveis de ultrassonografia o peso corpóreo inicial foi considerado como covariável. Todos os dados obtidos foram submetidos à análise de variância adotando-se o nível de significância de $10 \%$.

\subsection{RESULTADOS E DISCUSSÃO}

Os resultados obtidos para o ganho de peso do grupo controle e do grupo gama estão representados na tabela 1. Apesar do grupo suplementado com gama-orizanol ter obtido maior média de peso corporal $(347,34 \mathrm{~kg})$ em relação ao grupo controle $(325,86 \mathrm{~kg})$ ao final do período experimental, não foi observada diferença entre os grupos, já que os mesmos foram divididos em função da idade dos animais. Quando se avalia o ganho de peso diário, em porcentagem, não se observa diferença, e ambos os grupos ganharam 0,06\% por dia.

Concordam com este resultado Oliveira et al. (2010) que não encontraram diferença no ganho de peso dos equinos submetidos a exercício físico moderado e suplementados com gama-orizanol. Por outro lado, Gonzaga (2008) ao suplementar garanhões com gama-orizanol observou ganho médio diário de $0,1166 \%$.

Os resultados de escore de condição corporal (ECC) para os grupos controle e gama estão representados nas tabelas 2 e 3 .

Os animais suplementados com gama-orizanol obtiveram maior média de escore de condição corporal $(6,03)$ em relação aos animais do grupo controle $(5,80)$, sendo observado efeito de tratamento $(\mathrm{p}=0,05)$ e de tempo $(\mathrm{p}=0,04)$. Assim como o peso corporal, já discutido anteriormente, o grupo gama também iniciou o período experimental com maior valor de ECC. Porém, quando a evolução do ECC é avaliada ao longo do tempo, a redução do ECC foi maior no grupo gama $(10 \%)$ do que no grupo controle $(6,5 \%)$. Como a porcentagem do ganho de peso foi igual entre os grupos, é possível inferir que ocorreu maior mobilização lipídica e aumento de massa magra nos animais do grupo gama.

Os resultados obtidos para as diferentes mensurações pela ultrassonografia muscular estão apresentados na tabela 4. Não foram observadas diferenças em ambos os tratamentos para valores médios para a espessura de gordura na base da cauda; espessura do músculo Longissimus dorsi ou espessura de gordura do músculo Longissimus dorsi. Apesar disso, observando os valores de EGC, a média do grupo gama é numericamente menor do que o grupo controle. De acordo com Martins (2011), existe correlação entre a medida de EGC e o 
escore corporal. Gentry et al. (2004) observaram que o armazenamento de gordura na região da cauda é maior em relação a qualquer outra parte do corpo equino. Estes mesmos autores ainda afirmaram que a região da cauda é o primeiro local onde a gordura subcutânea será armazenada ou utilizada pelo animal, enquanto que na espessura de gordura lombar e na espessura da musculatura glútea, a magnitude dessas variações ocorre em menor escala.

Os valores médios para colesterol total, triglicérides, HDL-C, LDL-C e VLDL-C para os grupos controle e gama estão descritos na tabela 5. Foi observado efeito de tratamento $(\mathrm{p}=0,001)$ para colesterol total, onde o grupo suplementado obteve maior concentração média durante o período experimental $(113,99 \mathrm{mg} / \mathrm{dL})$ em relação ao grupo controle $(108,55$ $\mathrm{mg} / \mathrm{dL}$ ). Todos os valores encontrados para colesterol total, em todos os animais, independente do tempo e/ou tratamento, estão dentro da faixa de normalidade citada por Lumsden et al. (1980), de 69 - $150 \mathrm{mg} / \mathrm{dL}$ para cavalos de raças leves.

Foi verificado efeito ao longo do tempo experimental $(\mathrm{p}=0,0392)$ para triglicérides, onde o grupo suplementado obteve maior concentração média durante o período experimental $(57,43 \mathrm{mg} / \mathrm{dL})$ em relação ao grupo controle $(52,51 \mathrm{mg} / \mathrm{dL})$. Os valores obtidos para triglicérides encontram-se na faixa de normalidade $(<100 \mathrm{mg} / \mathrm{dL})$ de acordo com Carlson (2002).

Também foi observado efeito de tempo $(\mathrm{p}<0,001)$ para LDL-C, onde o grupo suplementado obteve maior concentração média durante o período experimental $(76,35$ mg/dL) em relação ao grupo controle $(73,67 \mathrm{mg} / \mathrm{dL})$. Para a fração HDL-C, foi observado efeito de tempo ao longo do período experimental $(\mathrm{p}=0,0251)$, onde o grupo suplementado obteve maior concentração média $(29,08 \mathrm{mg} / \mathrm{dL})$ em relação ao grupo controle $(26,89 \mathrm{mg} / \mathrm{dL})$. Da mesma forma, para a fração VLDL-C foi verificado efeito ao longo do tempo ( $p=0,0392)$, onde o grupo suplementado obteve maior concentração média durante o período experimental $(11,49 \mathrm{mg} / \mathrm{dL})$ em relação ao grupo controle $(10,50 \mathrm{mg} / \mathrm{dL})$.

Gonzaga et al. (2012) observaram aumento significativo dos valores médios de colesterol total e de LDL-C, suplementando garanhões com óleo de arroz semi-refinado rico em gama-orizanol em relação ao grupo controle. Estes autores também encontraram maior valor absoluto para todas as variáveis plasmáticas de lipídeos estudadas (HDL-C, VLDL-C, LDL-C, colesterol total e triglicérides) para os animais do grupo gama-orizanol, corroborando com os dados desta pesquisa. Frank et al. (2005) também observaram aumento do colesterol total e do LDL-C em éguas suplementadas com óleo de arroz bruto. Discordam destes resultados, pesquisas realizadas com humanos (MOST et al., 2005) e ratos (MINHAJUDDIN 
et al., 2005), onde foram verificadas redução dos níveis de colesterol total, triglicérides e de LDL-C associada ao uso do óleo de arroz e gama-orizanol.

\subsection{CONCLUSÕES}

A suplementação com gama-orizanol para equinos submetidos ao exercício aeróbio pode proporcionar redução do escore de condição corporal e elevar a concentração de colesterol plasmático. 


\section{REFERÊNCIAS}

BOFFI, F. M. Entrenamiento y Adaptación Muscular. Sustratos y Vías Metabólicas para la Producción de Energía. Revista Brasileira de Zootecnia, v. 37, p.197-201, 2008.

Suplemento especial.

CARLSON, G. P. Clinical chemistry tests. In: SMITH, B.P. (Ed.). Large animal internal medicine. 3. ed. St. Louis, Mosby, 2002. pp. 389-412.

DE GRAAF-ROELFSEMA, E.; KEIZER, H. A.; VAN BREDA, E.; WIJNBERG, I. D.; VAN DER KOLK, J. H. Hormonal responses to acute exercise, training and overtraining:a review with emphasis on the horse. Veterinary Quartely, v. 29, p. 82-101, 2007.

EVANS, D. Exercise testing in the field. In: HINCHCLIFF, K. W.; GEOR R. J.; KANEPS A. $\mathrm{J}$. Equine exercise physiology - the science of exercise in the athletic horse. Philadelphia: Elsevier, 2008. cap. 1-2, p. 13-27.

FRANK, N.; ANDREWS, F. M.; ELLIOTT, S. B.; LEW, J.; BOSTON, R. C. Effects of rice bran oil on plasma lipid concentrations, lipoprotein composition, and glucose dynamics in mares. Journal of Animal Science, v. 83, p. 2509-2518, 2005.

GENTRY, L. R.; THOMPSON, D. L.; GENTRY, G. T.; DEL VECCHIO, R. P.; DAVIS, K. A.; DEL VECCHIO, P. M. The relationship between body condition score and ultrasonic fat measurements in mares oh high versus low body condition. Journal of Equine Veterinary Science, v. 24, n. 5, p. 198-203, 2004.

GILLESPIE, M. S. Metabolic aspects of oryzanol in rats. 2003. 87 f. Dissertação (Mestrado) Louisiana State University, USA, 2003.

GONZAGA, I. V. F. Suplementação com óleo de arroz semi-refinado com alto teor de gama-orizanol. 2008. 87 f. Dissertação (Mestrado em Medicina Veterinária) - Faculdade de Medicina Veterinária e Zootecnia, Universidade de São Paulo, Pirassununga, 2008.

GONZAGA, I. V. F.; TAMAS, W. T.; ETCHICHURY, M.; GOBESSO, A. A. O. Qualidade espermática e perfil plasmático de lipídeos em garanhões suplementados com óleo de arroz semi-refinado com alto teor de gama-orizanol. Brazilian Journal of Veterinary Research and Animal Science, v. 49, p. 215-220, 2012.

HENNEKE, D. R.; POTTER, G. D.; KREIDER, J. L.; YEATS, B. F. Relationship between body condition score, physical measurements and body fat percentage in mares. Equine Veterinary Journal, v. 15, n. 4, p. 371-372, 1983.

LOWRY, G. F. Special unit and medical school laboratory technicians in New Zealand. A follow-up review and survey of training and qualifications 1970-1975. New Zealand Medicine Journal, v. 12, n. 5, p.579, 1977.

LUMSDEN, J. H.; ROWE, R.; MULLEN, K. Hematology and biochemistry reference values for the light horse. Canadian Journal of Comparative Medicine, v. 44, p. 32, 1980. 
MARTINS, R. A. D. T. Avaliação de escore corporal em equinos através da ultrasonografia. 2011. 81 f. Dissertação (Mestrado em Ciências) - Faculdade de Medicina Veterinária e Zootecnia, Universidade de São Paulo, Pirassununga, 2011.

NRC. NATIONAL RESEARCH COUNCIL. Nutrient requirements of horses. 6. ed. rev. Washington, D.C : National Academy Press, 2007. p. 341.

OLIVEIRA, R. N.; MARQUES JR., A. P.; XAVIER, P. R.; ALVES, G. E. S; PAES, P. R. O.; GOBESSO, A. A. O. Avaliação hematológica e bioquímica de equinos suplementados com óleo de arroz semi-refinado, rico em gama-orizanol. Arquivo Brasileiro de Medicina Veterinária e Zootecnia, v. 62, n. 5, p. 1043-1047, 2010.

PINTO, L.G. Avaliação do Exercitador Circular no Condicionamento Físico de Equinos de Iniciação Esportiva na Escola de Equitação do Exército. 2010. 79f. Dissertação (Mestrado em Ciências) - Instituto de Zootecnia, Universidade Federal Rural do Rio de Janeiro, Seropédica, 2010.

RIVERO, J. L. L.; RUZ, A.; MARTI-KORFF, S.; ESTEPA, J. C.; AGUILERA-TEJERO, E.; WERKMANN, J.; SOBOTTA, M.; LINDNER, A. Effects of intensity and duration of exercise on muscular responses to training of thoroughbred horses. Journal of Applied Physiology, v. 102, p. 1871-1882, 2007.

SAS User's Guide: Statistics Version 9.2. 2008. SAS Inst., Inc., Cary, NC. CD-ROM.

SEENE, T.; ALEV, K.; KAASIK, P.; PEHME, A.; PARRING, A. M. Endurance training: volume-dependent adaptation changes in myosin. International Journal Sports of Medicine, v. 26, p. 815-821, 2005. 
Tabela 1 - Peso médio, ganho de peso (GP), ganho médio diário (GMD), e porcentagem (\%) de ganho de peso total e diária para os grupos controle e gama ao final do período experimental

\begin{tabular}{lcc}
\hline \multirow{2}{*}{ Variável } & \multicolumn{2}{c}{ Tratamentos } \\
\cline { 2 - 3 } & Controle & Gama \\
\hline Peso médio $(\mathrm{kg})$ & 325,86 & 347,34 \\
GP $(\mathrm{kg})$ & 32,60 & 37,60 \\
GMD $(\mathrm{kg})$ & 0,18 & 0,21 \\
\% total & 10,09 & 10,82 \\
\% diária & 0,06 & 0,06 \\
\hline
\end{tabular}

Tabela 2 - Média de escore de condição corporal (ECC), erro padrão da média (EPM) e valor de p para os tratamentos controle e gama

\begin{tabular}{ccccccc}
\hline \multirow{2}{*}{ Variável } & \multicolumn{2}{c}{ Tratamentos } & \multirow{2}{*}{ EPM } & \multicolumn{3}{c}{ Valor de $\mathbf{p}$} \\
\cline { 2 - 3 } & Controle & Gama & & Tratamento & Tempo & Interação \\
\hline \multirow{2}{*}{ ECC } & $5,80^{\mathrm{a}}$ & $6,03^{\mathrm{b}}$ & 0,08 & 0,05 & 0,04 & 0,96
\end{tabular}

Letras diferentes na mesma linha diferem pelo teste $\mathrm{F}$

Tabela 3 - Médias de escore de condição corporal (HENNEKE et al., 1983) para os grupos controle e gama ao longo do período experimental

\begin{tabular}{lcccccccc}
\hline \multirow{2}{*}{ Grupos } & \multicolumn{8}{c}{ Tempo (dia) } \\
\cline { 2 - 9 } & D0 & D30 & D60 & D90 & D120 & D150 & D180 & Média \\
\hline Controle & 6,2 & 5,7 & 5,7 & 5,6 & 5,8 & 5,8 & 5,8 & 5,8 \\
Gama & 6,6 & 6,1 & 5,7 & 5,8 & 5,9 & 6,1 & 6 & 6,0 \\
\hline
\end{tabular}


Tabela 4 - Valores médios das medidas ultrasonográficas (em milímetros), erro padrão da média (EPM) e valor de significância para os grupos controle e gama

\begin{tabular}{|c|c|c|c|c|c|c|}
\hline \multirow{2}{*}{ Variável } & \multicolumn{2}{|c|}{ Tratamento } & \multirow{2}{*}{ EPM } & \multicolumn{3}{|c|}{ Valor de $P$} \\
\hline & Controle & Gama & & Tratamento & Tempo & Interação \\
\hline EGC & 18,26 & 15,23 & 0,74 & 0,64 & 0,28 & 0,50 \\
\hline EML & 80,90 & 81,28 & 0,99 & 0,87 & 0,24 & 0,25 \\
\hline EGL & 3,27 & 3,53 & 0,11 & 0,31 & 0,57 & 0,92 \\
\hline
\end{tabular}

$\overline{\mathrm{EGC}}$ = espessura de gordura na inserção da cauda; EML= espessura do músculo Longissimus dorsi; EGL= espessura de gordura do músculo Longissimus dorsi; EPM= erro padrão da média.

Tabela 5 - Médias de colesterol total, triglicérides, HDL-C, LDL-C e VLDL-C (mg/dL), erro padrão da média (EPM) e valor de p para os tratamentos controle e gama

\begin{tabular}{lcccccc}
\hline \multirow{2}{*}{ Variável } & \multicolumn{2}{c}{ Tratamentos } & \multirow{2}{*}{ EPM } & \multicolumn{3}{c}{ Valor de p } \\
\cline { 2 - 3 } \cline { 6 - 7 } & Controle & Gama & & Tratamento & Tempo & Interação \\
\hline Colesterol total & $108,55^{\mathrm{a}}$ & $113,99^{\mathrm{b}}$ & 3,85 & 0,001 & 0,3212 & 0,6155 \\
Triglicérides & 52,51 & 57,43 & 4,20 & 0,4115 & 0,0392 & 0,4041 \\
HDL-C & 26,89 & 29,08 & 1,17 & 0,1907 & 0,0251 & 0,5426 \\
LDL-C & 73,67 & 76,35 & 2,59 & 0,4666 & $<0,001$ & 0,3870 \\
VLDL-C & 10,50 & 11,49 & 0,84 & 0,4115 & 0,0392 & 0,0392 \\
\hline
\end{tabular}

Letras diferentes na mesma linha diferem pelo teste $\mathrm{F}$ 


\section{CAPÍtUlo II}

FREQUENCIA CARDÍACA DE EQUINOS SUBMETIDOS AO EXERCÍCIO AERÓBIO E SUPLEMENTADOS COM GAMA-ORIZANOL 


\section{RESUMO}

Com o objetivo de avaliar o efeito da suplementação com gama-orizanol em equinos submetidos a exercício aeróbio sobre a frequência cardíaca, foram utilizados dez cavalos da raça Puro Sangue Árabe, machos, castrados, com idade média de 35 $\pm 8,15$ meses e peso corporal médio de $375 \pm 22,78 \mathrm{~kg}$, ao início do período experimental, divididos em dois lotes de cinco animais cada, denominados grupos controle e gama. $\mathrm{O}$ experimento foi conduzido no Laboratório de Pesquisa em Alimentação e Fisiologia do Exercício de Equinos (LABEQUI), pertencente à FMVZ-USP, no Campus Administrativo de Pirassununga, São Paulo, adotandose o consumo diário individual de $2 \%$ do peso corpóreo, com base na matéria seca, sendo $50 \%$ de volumoso composto por feno de gramínea e 50\% de concentrado comercial. Em cada refeição, todos os animais receberam $50 \mathrm{~mL}$ de óleo vegetal, sendo que apenas o grupo gama recebeu o gama-orizanol (dez gramas diárias). Ambos os grupos foram exercitados em caminhador eletrônico, durante 60 minutos, na velocidade máxima de $12 \mathrm{~km} / \mathrm{h}$, cinco vezes por semana. Durante o período experimental de 180 dias, os equinos foram mensalmente avaliados através do uso de frequencímetro cardíaco durante o exercício. Foram obtidas as frequências cardíacas (FC) basal, máxima durante o trabalho (FC de pico), FC final, e FC aos 10 e 20 minutos após o fim do exercício. Foram observados efeitos de tempo para a FC basal $(\mathrm{p}=0,001)$, final $(\mathrm{p}=0,003)$, e ao final do exercício após $10(\mathrm{p}<0,001)$ e $20(\mathrm{p}=0,009)$ minutos. A FC após 20 minutos também demonstrou interação tempo*tratamento ( $p=0,05$ ), onde o grupo gama obteve menor média $(46,03 \mathrm{bpm})$ do que o grupo controle $(46,21 \mathrm{bpm})$, e ao longo dos 180 dias a média desta variável reduziu em 30\% para o grupo gama em relação ao controle (7\%). A suplementação com gama-orizanol de equinos submetidos ao exercício aeróbio pode reduzir o tempo de recuperação da frequência cardíaca após o esforço.

Palavras-chave: Cavalos. Exercitador circular. Frequência cardiaca. Gama-orizanol. 


\begin{abstract}
In order to evaluate the effect of supplementation with gamma-oryzanol in horses undergoing aerobic exercise were used ten Purebred Arabian horses, geldings, mean age 35 \pm 8.15 months and mean weight of $375 \pm 22.78 \mathrm{~kg}$ at the beginning of the experimental period, divided into two groups of five animals each, named "gama" and "control" groups. The experiment was conducted at the Laboratório de Pesquisa em Alimentação e Fisiologia do Exercício de Equinos (LABEQUI), belonging to FMVZ-USP, at Campus Administrativo de Pirassununga, São Paulo, adopting individual daily consumption of $2 \%$ of body weight, based on dry matter, $50 \%$ of forage composed of grass hay and $50 \%$ commercial concentrate. In each meal, the animals received $50 \mathrm{~mL}$ of vegetable oil, and only the group "gama" received the gammaoryzanol (ten grams daily). Both groups were trained in electronic walker for 60 minutes at a maximum speed of $12 \mathrm{~km} / \mathrm{h}$, five times a week. We obtained heart rates (HR) at baseline, during maximal work (HR peak), final HR and HR at 10 and 20 minutes after the end of the exercise. Time effects were observed for baseline HR $(p=0.001)$, final $(p=0.003)$, and at the end of the training after $10(\mathrm{p}<0.001)$ and $20(\mathrm{p}=0.009)$ minutes. The HR after 20 minutes also showed interaction time*treatment $(\mathrm{p}=0.05)$, the gama group had lower average $(46.03$ bpm) than the control group (46.21 bpm), and over the 180 days the average this variable reduced by $30 \%$ for the gama group compared to control $(7 \%)$. Supplementation with gamma-oryzanol of horses submitted to aerobic exercise can reduce the heart rate recovery after exercise.
\end{abstract}

Keywords: Gamma-oryzanol. Heart rate. Horse. Walker. 


\section{INTRODUÇÃO}

Nos cavalos de esporte a frequência cardíaca (FC) foi matéria de estudo durante muitos anos, ficando bem estabelecidas as diferenças raciais, etárias, de tamanho e treinamento (HODGSON; ROSE, 1994), sendo atualmente utilizada pela Federação Equestre Internacional (FEI), e figurando nas suas Normas do Enduro Equestre (FEI, 2012) como parâmetro para avaliar o estado físico dos cavalos em competições devido a sua estreita correlação com valores da bioquímica sanguínea.

A FC tem sido convencionalmente utilizada como indicadora das funções respiratórias e circulatórias do cavalo (LINDHOLM; SALTIN, 1974; HODGSON et al., 1994), e sua mensuração durante o exercício permite quantificar a intensidade da carga de trabalho e monitorar o condicionamento físico, constituindo-se numa importante ferramenta para a maximização de qualquer programa de treinamento, tanto para atletas da espécie humana (LINDINGER, 1999) como para a equina (TRILK, 2002).

O emprego de testes para a avaliação do desempenho atlético realizados a campo (pista), juntamente com as respostas fisiológicas obtidas pela ação do exercício e do treinamento, pode ser uma valiosa ferramenta para maximização dos resultados obtidos nas competições. O programa de treinamento deixa de ser realizado somente de maneira empírica tornando-se um processo técnico, com embasamento clínico e fisiológico (LINDNER et al., 2006).

A fisiologia do exercício, particularmente no que se refere ao estresse oxidativo, toma especial relevância no caso do enduro equestre, e as substancias antioxidantes ocupam lugar de destaque no estudo da prevenção do dano celular mediante a neutralização dos radicais livres produzidos em grande escala nos exercícios físicos prolongados, e cujos efeitos deletérios podem atingir e danificar diversos sistemas orgânicos (ETCHICHURY, 2010).

No segmento de cavalos de esporte, aumenta a cada dia a comercialização de suplementos nutricionais, como por exemplo, o gama-orizanol. Esta substância, extraída do farelo de arroz, tem sido utilizada na indústria farmacêutica e cosmética, assim como aditivo alimentar, devido à sua propriedade antioxidante (JULIANO et al., 2005).

O objetivo deste estudo foi avaliar o efeito da suplementação com gama-orizanol em equinos sobre os valores de frequência cardíaca antes, durante e após o exercício aeróbio. 


\subsection{MATERIAIS E MÉTODOS}

Todos os procedimentos utilizados neste estudo foram submetidos à avaliação do comitê de ética em experimentação animal da Faculdade de Medicina Veterinária e Zootecnia da Universidade de São Paulo, estando registrado sob o protocolo de número 1794/2009.

O experimento foi conduzido no Laboratório de Pesquisa em Alimentação e Fisiologia do Exercício em Equinos (LABEQUI), pertencente à Faculdade de Medicina Veterinária e Zootecnia da Universidade de São Paulo, situado no Campus Administrativo de Pirassununga, Estado de São Paulo, onde foram utilizados dez equinos da raça Puro Sangue Árabe, machos, castrados, hígidos, com idade média de $35 \pm 8,15$ meses e peso corporal médio de $375 \pm 22,78$ $\mathrm{kg}$ ao início do período experimental, alojados em piquetes.

Foi adotado o consumo diário individual de $2 \%$ do peso corporal, em matéria seca, sendo $50 \%$ concentrado e $50 \%$ volumoso, divididos em duas refeições diárias. O concentrado foi fornecido em comedouros individuais, em área de serviço, no sistema tipo "lanchonete", enquanto que o volumoso foi distribuído em manjedouras no piquete. As dietas foram compostas por feno de gramínea Cynodon sp, variedade Tifton 85 e concentrado comercial, além de sal mineralizado e água ad libitum, seguindo as recomendações estabelecidas no Nutrient Requeriments of Horses - NRC (2007) para equinos nesta categoria.

Foram compostos dois grupos de tratamento com cinco cavalos cada, sendo um grupo denominado "controle" e o outro "gama". O grupo gama recebeu cinco gramas de gamaorizanol puro, apresentado na forma de pó cristalino, e dissolvido em $50 \mathrm{~mL}$ de óleo vegetal, por refeição, sendo adicionado ao concentrado diretamente no comedouro. A inclusão de óleo vegetal se faz necessária devido à melhor biodisponibilidade do gama-orizanol em meio lipídico, como demonstrado por Gillespie (2003).

Todos os animais foram exercitados cinco vezes por semana, durante sessenta minutos, na velocidade máxima de $12 \mathrm{~km} / \mathrm{h}$, em exercitador circular mecânico para cavalos (Equiboard $^{\circledR}$ ), controlado eletronicamente. O protocolo de exercício foi dividido em seis estágios: ( $\left(^{\circ}\right) 10$ minutos na velocidade de $7 \mathrm{~km} / \mathrm{h} ;\left(2^{\circ}\right) 15$ minutos na velocidade de $10 \mathrm{~km} / \mathrm{h}$; $\left(3^{\circ}\right) 5$ minutos na velocidade de $12 \mathrm{~km} / \mathrm{h}$; (4 $\left.4^{\circ}\right) 5$ minutos na velocidade de $12 \mathrm{~km} / \mathrm{h}$; $\left(5^{\circ}\right) 15$ minutos na velocidade de $10 \mathrm{~km} / \mathrm{h} ;\left(6^{\circ}\right) 10$ minutos na velocidade de $7 \mathrm{~km} / \mathrm{h}$. Entre os estágios 3 e 4 ocorria a inversão de sentido do exercitador. De acordo com Pinto (2010), o uso do exercitador, apesar do menor gasto calórico proporcionado, em alguns aspectos fisiológicos, hematológicos e bioquímicos, produz efeitos no organismo semelhantes ao teste a campo, 
podendo ser considerado, sobretudo com o protocolo testado a $12 \mathrm{~km} / \mathrm{h}$, como um meio alternativo de treinamento e avaliação de equinos em fase inicial de treinamento, com economia de tempo e mão de obra.

Com a finalidade de mensurar a frequência cardíaca (FC), foram utilizados frequencímetros digitais (Garmin Forerunner $305^{\circledR}$ ) com cintas e adaptadores para uso em equinos $\left(\mathrm{V}-\mathrm{Max}^{\circledR}\right)$. O frequencímetro possui sistema de localização via satélite através de GPS (Global Positioning System), com mensuração da frequência cardíaca e da velocidade, gerando gráficos que permitem monitorar a FC durante o exercício. Estes gráficos são gerados através de programa específico (Garmin Training Center $^{\circledR}$ ) no qual pode ser obtida a FC, a qualquer momento do exercício, e de qualquer animal monitorado, formando um banco de dados completo sobre cada cavalo e seu treinamento.

A frequência cardíaca de todos os animais foi mensurada mensalmente, nos dias 0,30 , 60, 90, 120, 150 e 180 do período experimental. Em cada tempo foram obtidas cinco mensurações denominadas: FC basal (em repouso, antes do exercício), FC de pico (a máxima FC atingida pelo animal durante o exercício), FC final (obtidas imediatamente ao final do exercício), FC+10 (FC obtida com o animal em repouso, dez minutos após o fim do exercício), e FC+20 (FC obtida com o animal em repouso, vinte minutos após o fím do exercício). Através do programa computacional já mencionado foram coletados os dados minuto a minuto da FC de todos os animais, com a finalidade de avaliar cada faixa de velocidade e a frequência cardíaca obtida entre os grupos de tratamento.

Para obtenção da frequência cardíaca basal, os animais permaneceram dez minutos em repouso, sem manipulação humana. Em seguida, os cavalos eram colocados no exercitador, sendo iniciado o trabalho programado. Após o término do mesmo, os equinos permaneceram 20 minutos em repouso com o frequencímetro, simulando uma avaliação do tempo de recuperação em provas de enduro equestre.

$\mathrm{O}$ delineamento experimental utilizado foi inteiramente casualizado com medidas repetidas no tempo, com dois tratamentos, e cinco repetições por tratamento. Os dados foram analisados utilizando o procedimento PROC MIXED (Versão 9.2, SAS Institute, Cary, NC 2010) após verificação da normalidade dos resíduos pelo teste de Shapiro-Wilk (PROC UNIVARIATE). Foi utilizado o efeito aleatório animal dentro dos tratamentos. O método de Kenward-Rogers foi usado para calcular os graus de liberdade do denominador do teste F. As análises foram realizadas como medidas repetidas no tempo considerando como efeito fixo o tempo (D0, D30, D60...), tratamento (com ou sem suplementação), e interação (tempo*tratamento). Os tratamentos foram confrontados dentro de cada tempo através da 
opção PDIFF (Perceptual Diff) com as médias ajustadas obtidas por meio do LSMEANS (Least Squares Means).

\subsection{RESULTADOS E DISCUSSÃO}

Os resultados obtidos para as médias da frequência cardíaca de ambos os grupos ao final do período experimental estão apresentados na tabela 6.

Tabela 6 - Médias de frequência cardíaca basal, de pico, final, e de recuperação com 10 e 20 minutos (FC, em batimentos por minuto - bpm), erro padrão da média (EPM) e valor de significância para os grupos controle e gama

\begin{tabular}{lccccccc}
\hline \multirow{2}{*}{ Variável } & \multicolumn{2}{c}{ Tratamento } & \multirow{2}{*}{ EPM } & \multicolumn{3}{c}{ Valor de P } \\
\cline { 2 - 3 } FC basal & Controle & Gama & & & Tratamento & Tempo & Interação \\
\hline FC de pico & 41,80 & 40,37 & 0,67 & 0,61 & 0,001 & 0,84 \\
FC final & 154,86 & 147,09 & 3,99 & 0,45 & 0,48 & 0,17 \\
FC +10 & 63,79 & 66,94 & 2,79 & 0,52 & 0,003 & 0,07 \\
FC +20 & 48,51 & 50,54 & 1,53 & 0,67 & $<0,0001$ & 0,73 \\
\hline
\end{tabular}

Os animais suplementados com gama-orizanol obtiveram menor média $(40,37 \pm 5,49$ bpm) para a frequência cardíaca (FC) basal em relação ao controle $(41,80 \pm 5,76$ bpm), apresentando efeito de tempo $(\mathrm{p}=0,001)$ para esta variável. Segundo Erickson (1989), os aumentos na FC basal têm diversas causas além do trabalho físico, como por exemplo, apreensão, ansiedade, fadiga, desconforto ou dor por qualquer causa e por disfunção respiratória. Apesar disso, a média da FC basal ao longo do tempo foi reduzida em 15,2\% para o grupo gama e 6,3\% para o grupo controle.

Em relação à $\mathrm{FC}$ de pico, ou seja, a máxima $\mathrm{FC}$ atingida pelo animal durante o exercício, o grupo controle obteve média de $154,86 \pm 31,34$ bpm e o grupo suplementado $147,09 \pm 35,37$ bpm, embora não tenha sido observada diferença entre os tratamentos.

A FC final média do grupo controle $(63,79 \pm 21,07 \mathrm{bpm})$ foi menor do que a observada para o grupo gama $(66,94 \pm 24,94 \mathrm{bpm})$, apresentando efeito de tempo $(\mathrm{p}=0,003)$. Porém 
também foi observada interação tempo*tratamento $(\mathrm{p}=0,07)$, e quando as médias das FC finais são avaliadas ao longo do tempo, o grupo gama obteve $44 \%$ de redução da FC final, enquanto que no grupo controle esta redução foi de apenas $9,6 \%$.

Sobre a frequência cardíaca de recuperação, mensurada dez minutos após o fím do exercício $(\mathrm{FC}+10)$, o grupo controle demonstrou menor média $(48,52 \pm 9,44 \mathrm{bpm})$ do que o grupo gama $(50,54 \pm 15,13 \mathrm{bpm})$, sendo observado efeito de tempo $(\mathrm{p}<0,0001)$, com redução ao longo do tempo de 31,5\% da FC para o grupo gama, e de 16,5\% para o controle. Vinte minutos após o fim do exercício, o grupo gama obteve menor FC $(46,03 \pm 10,75 \mathrm{bpm})$ do que o grupo controle $(46,21 \pm 9,48 \mathrm{bpm})$, com efeito de tempo $(\mathrm{p}=0,009)$ e interação tempo*tratamento $(\mathrm{p}=0,05)$. O grupo gama obteve menor média $(46,03 \mathrm{bpm})$ do que o grupo controle (46,21bpm), e ao longo dos 180 dias a média desta variável reduziu em $30 \%$ para o grupo gama em relação ao controle (7\%).

A redução da FC 20 minutos após o fim do exercício pode estar diretamente ligada ao treinamento e à suplementação com gama-orizanol, pela interação ente tempo e tratamento observada. Em velocidades de corrida submáximas, a FC torna-se menor com a progressão do treinamento e o aumento da capacidade aeróbia, ou seja, um animal treinado executa exercício igual ao que fazia antes, com menor FC (KOBAYASHI et al., 1999; OHMURA et al., 2002).

Também foram analisadas as frequências cardíacas dos animais de acordo com o estágio do exercício, seguindo o esquema de trabalho apresentado anteriormente, e os resultados estão demonstrados na tabela 7.

Tabela 7 - Médias de frequência cardíaca (bpm) dos grupos gama e controle nos diferentes estágios de exercício, erro padrão da média (EPM) e valor de $p$

\begin{tabular}{ccccccccc}
\hline \multirow{2}{*}{ Estágio } & \multirow{2}{*}{ Velocidade } & \multicolumn{2}{c}{ Tratamento } & & \multicolumn{3}{c}{ Valor de p } \\
\cline { 3 - 4 } & & Controle & Gama & & Tratamento & Tempo & Interação \\
\hline 1 & $7 \mathrm{~km} / \mathrm{h}$ & 88,15 & 88,54 & 2,71 & 0,95 & 0,56 & 0,03 \\
2 & $10 \mathrm{~km} / \mathrm{h}$ & 111,97 & 106,09 & 3,33 & 0,41 & 0,40 & 0,34 \\
3 & $12 \mathrm{~km} / \mathrm{h}$ & 120,06 & 114,14 & 3,59 & 0,41 & 0,14 & 0,32 \\
4 & $12 \mathrm{~km} / \mathrm{h}$ & 117,65 & 111,71 & 3,43 & 0,40 & 0,16 & 0,31 \\
5 & $10 \mathrm{~km} / \mathrm{h}$ & 117,74 & 109,94 & 3,68 & & 0,30 & 0,04 & 0,44 \\
6 & $7 \mathrm{~km} / \mathrm{h}$ & 96,41 & 89,89 & 3,76 & 0,40 & 0,01 & 0,21 \\
\hline
\end{tabular}

Trabalhando com cavalos em exercitador múltiplo, Pinto (2010) constatou que a frequência cardíaca acompanhou diretamente a velocidade, ou seja, quando esta aumentou, 
aquela também se elevou, mostrando evidente aumento em relação ao incremento da intensidade de esforço, o que também foi encontrado no presente estudo.

Foi observada interação tempo-tratamento ( $\mathrm{p}=0,03)$, com média de $88,54 \mathrm{bpm}$ para o grupo gama contra $88,15 \mathrm{bpm}$ do grupo controle na velocidade de $7 \mathrm{~km} / \mathrm{h}$, no estágio 1 , onde os cavalos iniciavam o trabalho. Este resultado pode ter sido influenciado pela ansiedade e/ou excitação inicial dos animais ao começar o exercício, como já discutido.

Nos estágios 2, 3 e 4, embora não tenha ocorrido diferença, pode ser notado que o grupo gama obteve numericamente a menor média de FC em relação ao grupo controle. Ao longo do tempo, podemos observar que os animais suplementados com gama-orizanol obtiveram menor média $(109,94 \pm 30,37 \mathrm{bpm})$ do que os animais controle $(117,74 \pm 30,67 \mathrm{bpm})$ na velocidade de $10 \mathrm{Km} / \mathrm{h}$, no estágio 5, com efeito de tempo (p=0,04); e no estágio seguinte (6), a $7 \mathrm{Km} / \mathrm{h}$, também foi verificada menor FC para o grupo gama $(89,89 \pm 29,62 \mathrm{bpm}) \mathrm{em}$ relação ao animais sem suplementação $(96,41 \pm 32,96$ bpm), e novamente observado efeito de tempo ( $\mathrm{p}=0,01)$. Esta menor $\mathrm{FC}$ do grupo gama nos estágios finais de trabalho pode explicar a menor FC mensurada aos vinte minutos após o final do exercício (FC+20).

A redução da FC pode estar relacionada com a adaptação do tipo de fibra muscular dos animais. Soncin (2012) constatou aumento na quantidade de fibras tipo IIA e IIX e redução nas fibras tipo I no período pós-suplementação com gama-orizanol em potros em crescimento. Segundo Howley (2000), as fibras do tipo IIA possuem características tanto oxidativa como glicolítica, demonstrando serem fibras extremamente adaptáveis, podendo, com o treinamento elevar sua capacidade oxidativa a níveis iguais aos das fibras tipo I. Equinos e humanos treinados são mais aptos a utilizar lipídeos para produzir energia do que carboidratos, e indivíduos treinados conseguem atrasar o início da fadiga por depleção de glicogênio (MARLIN; NANKERVINS, 2002) e aumentam a capacidade de utilização dos triglicérides pelo músculo, devido a uma maior quantidade de enzimas envolvidas na $\beta$ oxidação, metabolismo do ciclo de Krebs e a cadeia de transporte de elétrons (LAWRENCE,1994; McARDLE et al., 1998). Considerando esse fato, é provável que a característica antioxidante do gama-orizanol possa reduzir o estresse oxidativo das fibras musculares, postergando a fadiga, e refletindo positivamente na redução da frequência cardíaca. 


\subsection{CONCLUSÕES}

A suplementação com gama-orizanol de equinos submetidos ao exercício aeróbio pode melhorar a recuperação da frequência cardíaca após o esforço. 


\section{REFERÊNCIAS}

ERICKSON, H. H.; LUNDEN, C. S.; ERICKSON, B. K. Heart rate monitoring. Equine Veterinary Data, v. 11, n. 7, p. 170-173, 1989.

ETCHICHURY, M.; GOBESSO, A. O. O. Efeitos da suplementação endovenosa com selênio e vitamina E no sistema glutationa e enzimas musculares de cavalos de enduro. Revista Brasileira de Medicina Equina, v. 30, p. 8-11, 2010.

FEI. FÉDÉRATION EQUESTRE INTERNATIONALE. Endurance rules. Disponível em: <http://www.fei.org/sites/default/files/Endurance_rules_2009\%20reviewed\%20January\%202 011\%20BLACK_0.pdf> Acesso em: 15 abr. 2012.

GILLESPIE, M. S. Metabolic aspects of oryzanol in rats. $87 \mathrm{f}$. Dissertação (Mestrado) Louisiana State University, USA, 2003.

HODGSON, D. R.; DAVIS, R. E.; McCONAGHY, F. F. Thermoregulation in the horse in response to exercise. British Veterinary Journal, v. 150, p. 35-42, 1994.

HODGSON, D. R.; ROSE, R. J. The athletic horses: principles and practice of equine sports medicine. 1. ed. Philadelphia: Saunders, 1994. 497 p.

JULIANO, C.; COSSU, M.; ALAMANNI, M. C.; PIU, L. Antioxidant activity of gammaoryzanol: Mechanism of action and its effect on oxidative stability of pharmaceutical oils. International Journal of Pharmaceutics, v. 299, p. 146-154, 2005.

KOBAYASHI, M.; KURIBARA, K.; AMADA, A. Application of V200 values for evaluation of training effects in the young thoroughbred under field conditions. Equine Veterinary Journal, v. 30, p. 159-162, 1999. Supplement.

LINDHOLM, A.; SALTIN, B. The physiological and biochemical response of standardbred horses to exercise of varying speed and duration. Acta Veterinaria Scandinavica, v. 15, p. 310-324, 1974.

LINDNER, A.; SIGNORINI, R.; BRERO, L.; ARN, E.; MANCINI, R.; ENRIQUE, A. Effect of conditioning horses with short intervals at high speed on biochemical variables in blood.

Equine Veterinary Journal, v. 36, p. 88-92, 2006. Supplement.

LINDINGER, M. I. Exercise in the heat: thermoregulatory limitations to performance in humans and horse. Canadian Journal of Applied Physiology, v. 24, p. 135-146, 1999.

McARDLE, W. D.; KATCH, F. I.; KATCH, V. L. Caboidratos, gorduras e proteínas. In:__. Fisiologia do exercício: energia, nutrição e desempenho humano. 4. ed. Rio de Janeiro: Guanabara Koogan, 1998. p. 12-22.

MARLIN, D.; NANKERVIS, K. Equine exercise physiology. Oxford: Blackwell Science, 2002. 296 p. 
NRC. NATIONAL RESEARCH COUNCIL. Nutrient requirements of horses. 6. ed. rev. Washington, D.C : National Academy Press, 2007. p. 341.

PINTO, L.G. Avaliação do Exercitador Circular no Condicionamento Físico de Equinos de Iniciação Esportiva na Escola de Equitação do Exército. 2010. 79 f. Dissertação (Mestrado em Ciências) - Instituto de Zootecnia, Universidade Federal Rural do Rio de Janeiro, Seropédica, 2010.

OHMURA, H.; HIRAGA, A.; MATSUI, A.; AIDA, H.; INOUE, Y.; SAKAMOTO, K.; TOMITA, M.; ASAI, Y. Changes in running velocity at heart rate 200 beats/min (V200) in young Thoroughbred horses undergoing conventional endurance training. Equine Veterinary Journal, v. 34, p. 634-635, 2002.

SAS. User's Guide: Statistics Version 9.2. 2008. SAS Inst., Inc., Cary, NC. CD-ROM.

SONCIN, M. R. S. P. Utilização do óleo de arroz na alimentação de equinos em crescimento. 2012. 98 f. Tese (Doutorado em Zootecnia) - Universidade Estadual de Maringá, Maringá, 2012.

TRILK, J. L. A lactate-guided conditioning programme to improve endurance performance. Equine Veterinary Journal Supplement, n. 34, p.122-125, 2002. 


\section{CONCLUSÕES GERAIS}

A suplementação com gama-orizanol para equinos submetidos ao exercício aeróbio pode proporcionar redução do escore de condição corporal, elevar a concentração de colesterol plasmático e ainda melhorar a recuperação da frequência cardíaca após o esforço.

Há crescente utilização e interesse sobre os efeitos desta substância, principalmente no meio esportivo, buscando melhor desempenho nas competições, porém, os dados existentes na literatura são escassos, e aqueles existentes são conflitantes ou divergem em relação à forma, teor ou origem do gama-orizanol utilizado (óleo de farelo de arroz semi-refinado ou bruto), raça, sexo ou idade dos animais.

A proposta inicial deste experimento consistia na realização de biópsias musculares dos animais, verificando o efeito do gama-orizanol sobre as fibras musculares, o teor de glicogênio, tamanho e capilaridade das mesmas. Porém, há dificuldade em encontrar locais de processamento e análise deste tipo de material, com poucos laboratórios e estes com alta demanda, sendo a maior parte laboratórios de fisiologia humana. 


\section{IMPLICAÇÕES}

As pesquisas com gama-orizanol em equinos devem ser estimuladas, principalmente na área da fisiologia esportiva (inclusive a nível molecular, com marcadores), investigando a absorção e metabolismo do princípio ativo em cavalos, no sentido de comprovar os resultados da suplementação de cavalos com gama-orizanol em relação à frequência cardíaca. Este parâmetro é de fundamental importância para participação e classificação em provas de enduro equestre (onde os animais da raça Puro Sangue Árabe são os maiores representantes), e a obtenção de menores valores de frequência cardíaca de recuperação pode definir o resultado da competição.

O impacto econômico da utilização desta substância também deve ser estudado, considerando que seu custo é elevado (cinco quilos de gama-orizanol cristalino, em pó, custam aproximadamente US\$ 2 mil), o que deve ser idealizado em escala de produção industrial e comercialização.

Apesar de ter sido considerada uma substância proibida no Regulamento Veterinário de 2009 da Federação Equestre Internacional (FEI), níveis padronizados sobre os efeitos e detecção em cavalos não estavam disponíveis, e a partir de Janeiro de 2013, o gama-orizanol foi retirado da listagem de substâncias consideradas doping. Apesar disto, algumas federações europeias, em campeonatos nacionais, não homologados pela FEI, mantém a proibição. 
APÊNDICES 
APÊEDICE A - Tabela 1 - Divisão dos animais segundo tratamento, peso (kg) e idade (meses) no início do período experimental

\begin{tabular}{cccc}
\hline Tratamento & Animal & Peso inicial & Idade \\
\hline \multirow{4}{*}{ Controle } & Malcon & 330 & 26 \\
& Maximus & 382 & 39 \\
& L'espoir & 370 & 48 \\
& Shawan & 367 & 36 \\
& Jaffar & 368 & 42 \\
\hline \multirow{6}{*}{ Gama } & Britan & 378 & 25 \\
& Darius & 393 & 26 \\
& Ramsey & 363 & 33 \\
& Jazz & 417 & 47 \\
& Taleeze & 390 & 36 \\
\hline
\end{tabular}


APÊNDICE B - Tabela 2 - Análise bromatológica do feno de gramínea utilizado

\begin{tabular}{lc}
\hline ÍNDICES & RESULTADOS $(\%)$ \\
\hline Matéria Seca & 91,15 \\
Matéria Mineral & 5,31 \\
Proteína Bruta & 7,12 \\
Extrato Etéreo & 1,11 \\
Fibra em Detergente Neutro & 70,52 \\
Fibra em Detergente Ácido & 35,70 \\
Amido & 1,24 \\
Cálcio & 0,49 \\
Fósforo & 0,22 \\
\hline
\end{tabular}


APÊNDICE C - Tabela 3 - Análise bromatológica do concentrado comercial utilizado

\begin{tabular}{lc}
\hline ÍNDICES & RESULTADOS (\%) \\
\hline Matéria Seca & 89,80 \\
Matéria Mineral & 6,59 \\
Proteína Bruta & 17,45 \\
Extrato Etéreo & 5,45 \\
Fibra em Detergente Neutro & 31,38 \\
Fibra em Detergente Ácido & 16,24 \\
Amido & 24,25 \\
Cálcio & 1,12 \\
Fósforo & 0,69 \\
\hline
\end{tabular}


APÊNDICE D - Figura 1 - Locais de avaliação do escore corporal

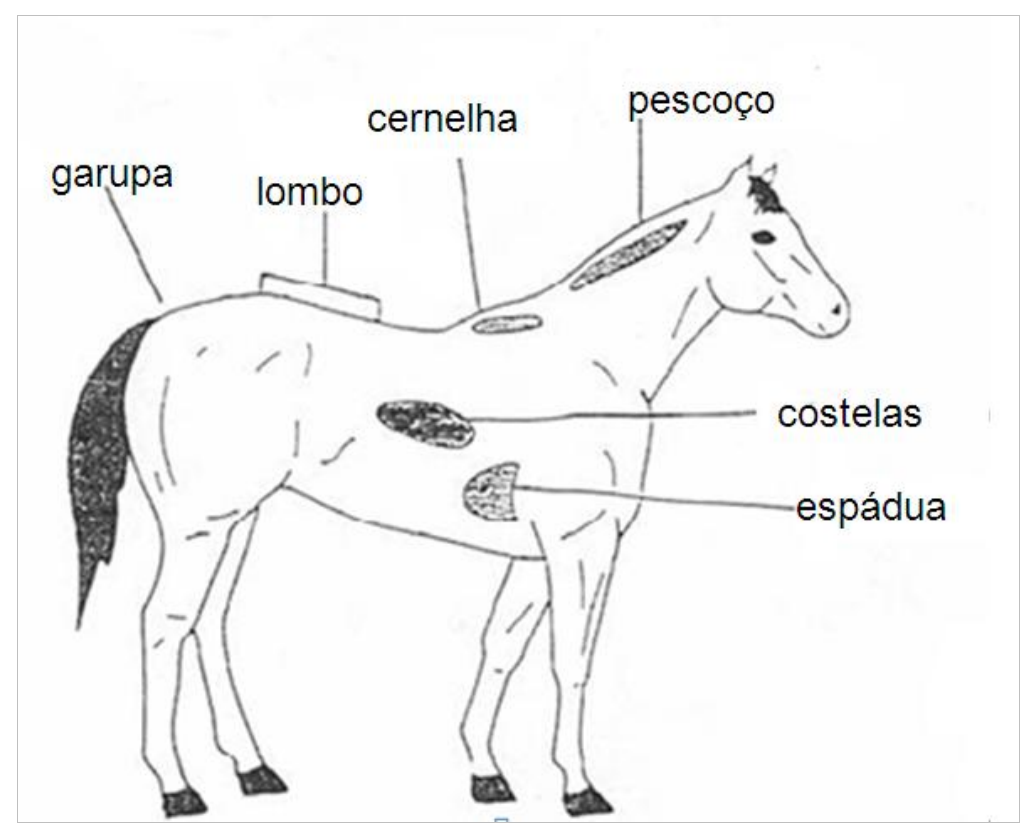

Fonte: Adaptado de Henneke et al. (1983) 
APÊNDICE E - Quadro 1 - Escore corporal em equinos

\section{1- Emaciado}

Processo espinhoso, costela, inserção da cauda. Ílio e ísquio proeminentes. Estrutura óssea da cernelha, espádua e pescoço facilmente visíveis. Não se observa presença de gordura em nenhuma parte do corpo animal.

\section{2- Muito magro}

Gordura cobrindo a base dos processos espinhosos. Extremidade dos processos transversos das vértebras lombares arredondadas. Costelas, inserção da cauda, ílio e ísquio proeminentes. Estruturas ósseas da cernelha, espádua e pescoço menos visíveis.

\section{3- Magro}

Gordura cobrindo a metade dos processos espinhosos. Processos transversos das vértebras lombares não são palpáveis. Pouca gordura cobrindo as costelas. Processo espinhoso e costelas facilmente visíveis. Inserção de cauda proeminente, porém, as vertebras não são visíveis. Íleo e ísquio arredondados, porém ainda visíveis. Estruturas ósseas da cernelha, espádua menos visíveis.

\section{4- Moderadamente magro}

Sulco ao longo da região lombar. Espaço entre as costelas visíveis. Gordura pode ser palpada na inserção da cauda, e sua proeminência depende da conformação do animal. ílio e ísquio não são visíveis. Estrutura óssea da cernelha, espádua com alguma cobertura de gordura.

5- Moderado (ideal)

Costelas não são visíveis, porém, facilmente palpadas. Gordura na inserção da cauda se torna esponjosa. Cernelha arredondada, cobrindo o processo espinhoso. Espádua e pescoço ligados suavemente ao corpo do animal.

6- Moderadamente gordo

Pode haver um sulco suave ao longo do dorso/lombo. Gordura cobrindo as costelas. Gordura mais macia na inserção da cauda. Gordura começa a ser depositada atrás e sobre a espádua e pescoço.

7- Gordo

Pode haver um sulco suave ao longo do dorso/lombo. Costelas podem ser palpadas individualmente, com depósito de gordura entre elas. Gordura mais macia na inserção da cauda. Gordura depositada atrás e sobre a espádua e pescoço.

8- Obeso

Depressão ao longo do dorso/lombo. Costelas são difíceis de serem palpadas. Gordura da inserção da cauda torna-se muito macia. Área ao redor da cernelha e atrás da espádua com muita gordura. Pescoço espesso. Gordura depositada na parte interna e posterior das patas traseiras do animal.

\section{9- Muito obeso}

Depressão evidente ao longo do dorso/lombo. Acúmulo de gordura sobre as costelas, formado placas. Acúmulo de gordura sobre a inserção da cauda, atrás da espádua e pescoço, formando dobras na pele. Gordura depositada na parte interna e posterior das patas traseiras do animal, formando dobras.

Fonte: (HENNEKE et al.,1983) 
APÊNDICE F - Figura 2 - Monitoramento cardíaco

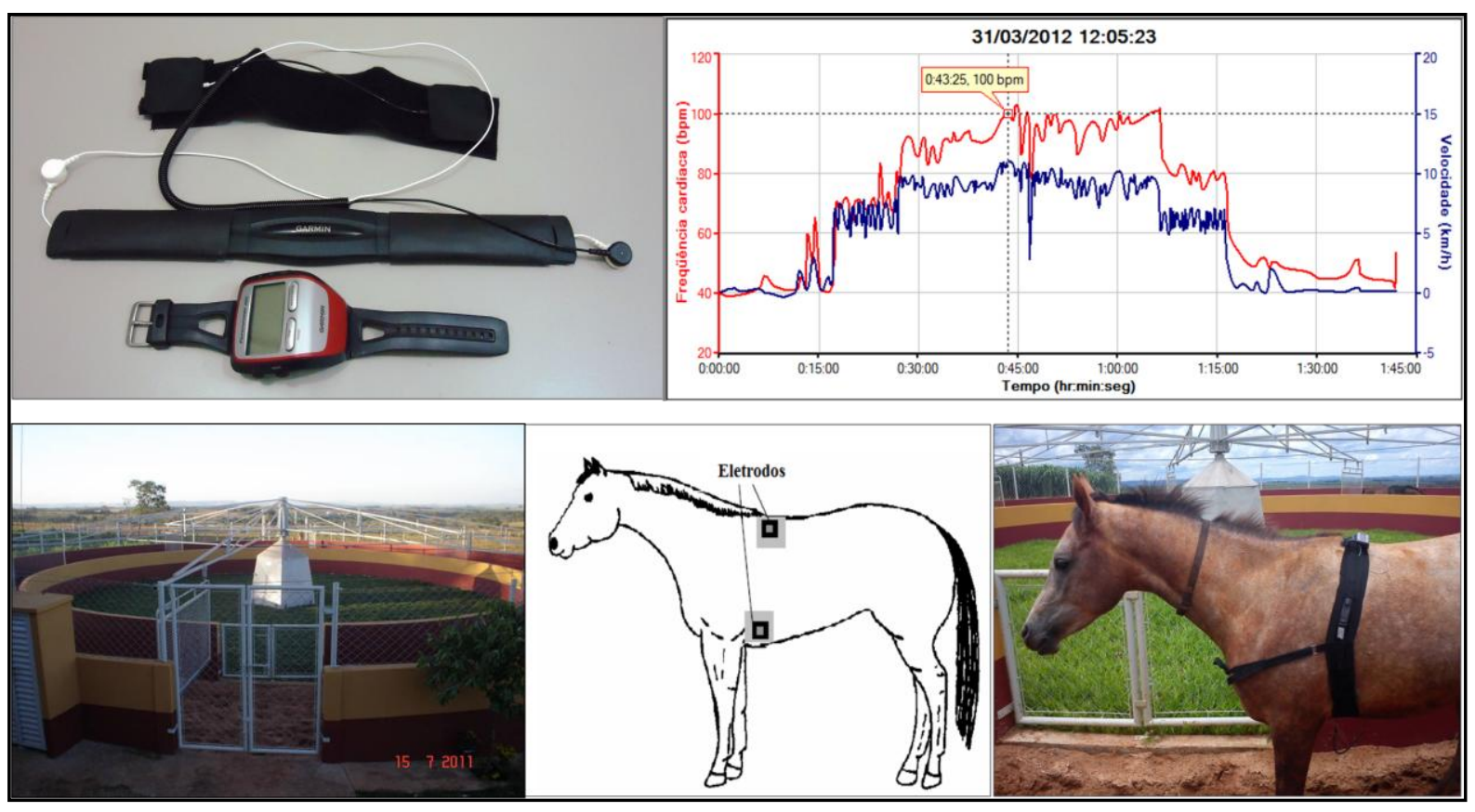


APÊNDICE G - Tabela 4 - Médias e desvio padrão da frequência cardíaca basal (em batimentos por minuto) do grupo controle e suplementado (gama), em função do tempo durante o período experimental

\begin{tabular}{cccc}
\multirow{2}{*}{ Tempo (dias) } & \multicolumn{2}{c}{ Tratamento } & CV (\%) \\
\cline { 2 - 3 } & Controle & Gama & \\
\hline 0 & $44,8 \pm 4,76$ & $43,4 \pm 9,26$ & 15,84 \\
30 & $44,6 \pm 4,28$ & $42,0 \pm 6,12$ & 11,93 \\
60 & $43,2 \pm 3,27$ & $43,2 \pm 3,11$ & 6,97 \\
90 & $40,6 \pm 2,51$ & $39,2 \pm 3,96$ & 8,05 \\
120 & $38,6 \pm 2,07$ & $38,2 \pm 3,19$ & 6,63 \\
150 & $38,8 \pm 0,84$ & $39,8 \pm 3,11$ & 5,63 \\
180 & $42,0 \pm 13,02$ & $36,8 \pm 6,26$ & 25,41 \\
\hline
\end{tabular}


APÊNDICE H - Figura 3 - Frequência cardíaca basal (FC basal), em batimentos por minuto (bpm), ao longo do tempo para os grupos controle e gama

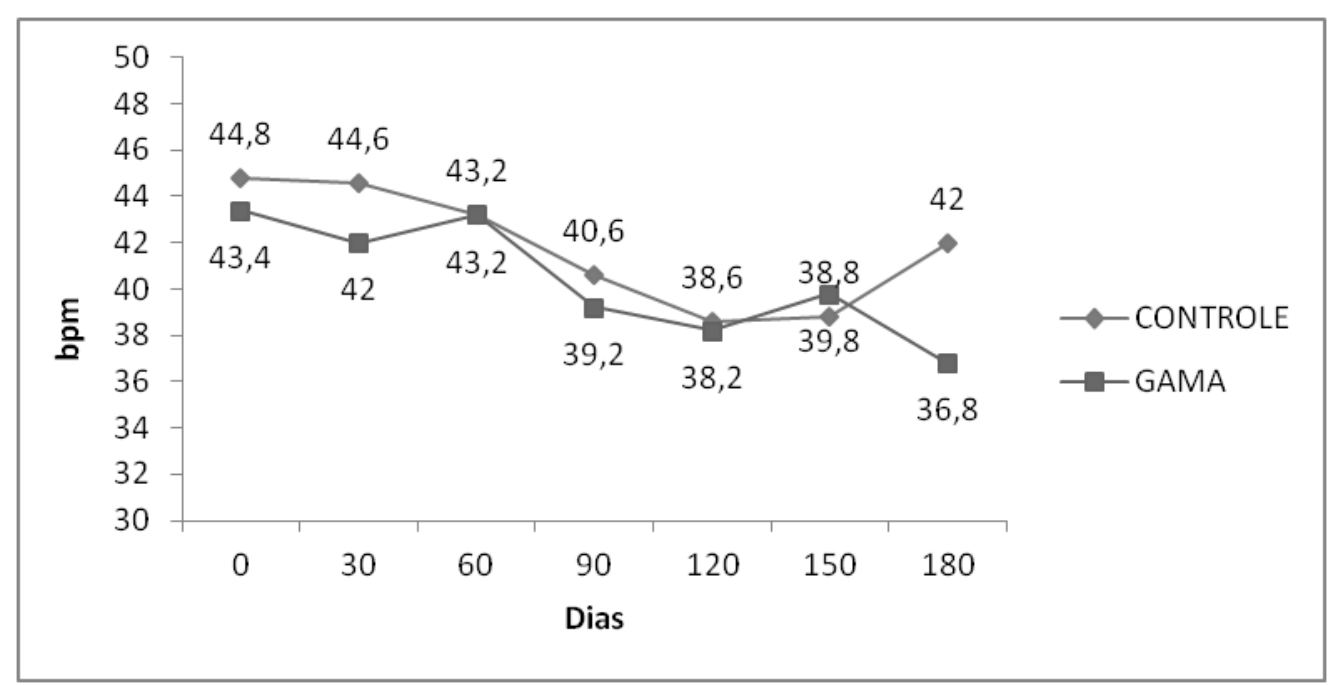


APÊNDICE I - Tabela 5 - Médias e desvio padrão da frequência cardíaca final (em batimentos por minuto) do grupo controle e suplementado (gama), em função do tempo durante o período experimental

\begin{tabular}{cccc}
\multirow{2}{*}{ Tempo (dias) } & \multicolumn{2}{c}{ Tratamento } & CV (\%) \\
\cline { 2 - 3 } & Controle & Gama & \\
\hline 0 & $60,4 \pm 13,15$ & $79,2 \pm 14,77$ & 23,63 \\
30 & $74,2 \pm 23,25$ & $65,6 \pm 7,50$ & 24,19 \\
60 & $51,25 \pm 5,62$ & $88,8 \pm 48,78$ & 55,35 \\
90 & $74,0 \pm 35,78$ & $62,4 \pm 20,77$ & 41,43 \\
120 & $56,5 \pm 5,80$ & $66,40 \pm 17,30$ & 22,2 \\
150 & $71,6 \pm 26,24$ & $62,0 \pm 19,70$ & 33,61 \\
180 & $54,6 \pm 12,16$ & $44,2 \pm 4,92$ & 20,89 \\
\hline
\end{tabular}


APÊNDICE J - Figura 10 - Frequência cardíaca final (FC final), em batimentos por minuto (bpm), ao longo do tempo para os grupos controle e gama

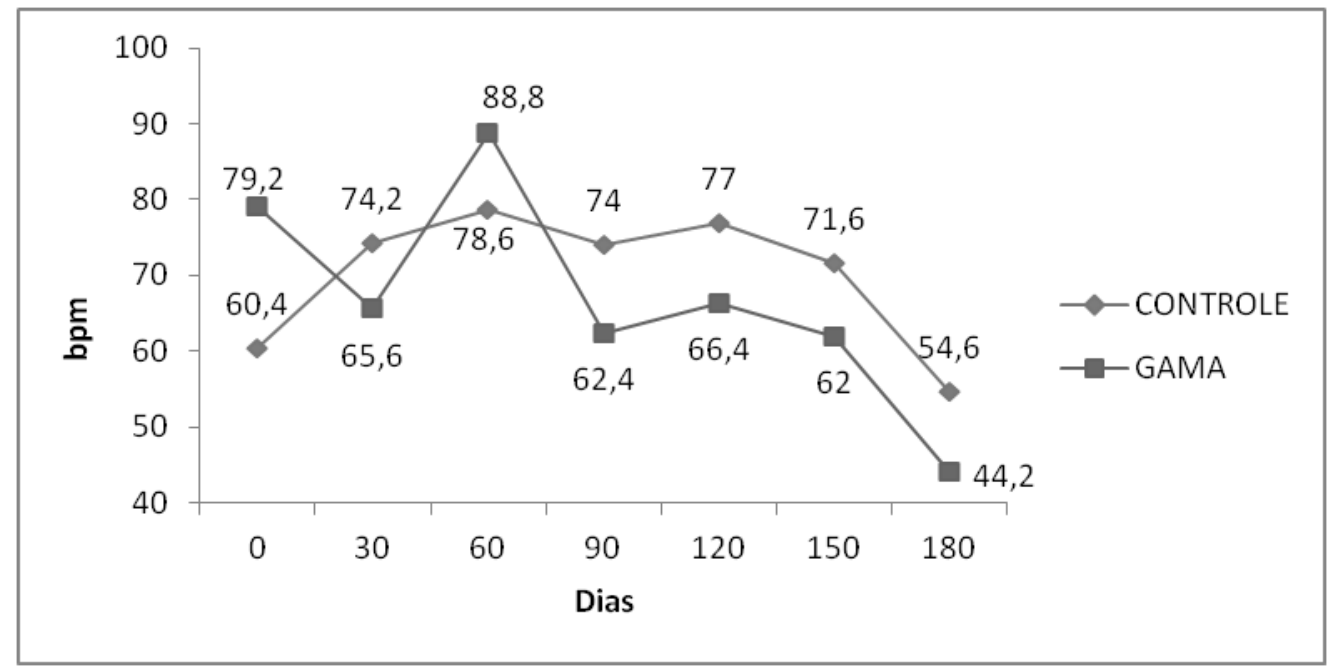


APÊNDICE K - Tabela 6 - Médias e desvio padrão da frequência cardíaca de recuperação, 10 minutos após o fim do exercício (em batimentos por minuto) do grupo controle e suplementado (gama), em função do tempo durante o período experimental

\begin{tabular}{|c|c|c|c|}
\hline \multirow{2}{*}{ Tempo (dias) } & \multicolumn{2}{|c|}{ Tratamento } & \multirow{2}{*}{ CV (\%) } \\
\hline & Controle & Gama & \\
\hline 0 & $49,60 \pm 3,51$ & $57,0 \pm 14,93$ & 20,53 \\
\hline 30 & $51,75 \pm 6,5$ & $54,0 \pm 8,28$ & 13,54 \\
\hline 60 & $55,40 \pm 8,0$ & $66,2 \pm 27,15$ & 32,41 \\
\hline 90 & $46,75 \pm 4,92$ & $47,0 \pm 4,53$ & 9,38 \\
\hline 120 & $43,40 \pm 4,39$ & $42,0 \pm 4,36$ & 9,81 \\
\hline 150 & $51,60 \pm 19,32$ & $48,6 \pm 14,29$ & 32,14 \\
\hline 180 & $41,40 \pm 3,51$ & $39,0 \pm 4,53$ & 10,01 \\
\hline
\end{tabular}


APÊEDICE L - Figura 5 - Frequência cardíaca de recuperação, em batimentos por minuto (bpm), 10 minutos após o final do exercício $(\mathrm{FC}+10)$ ao longo do tempo para os grupos controle e gama

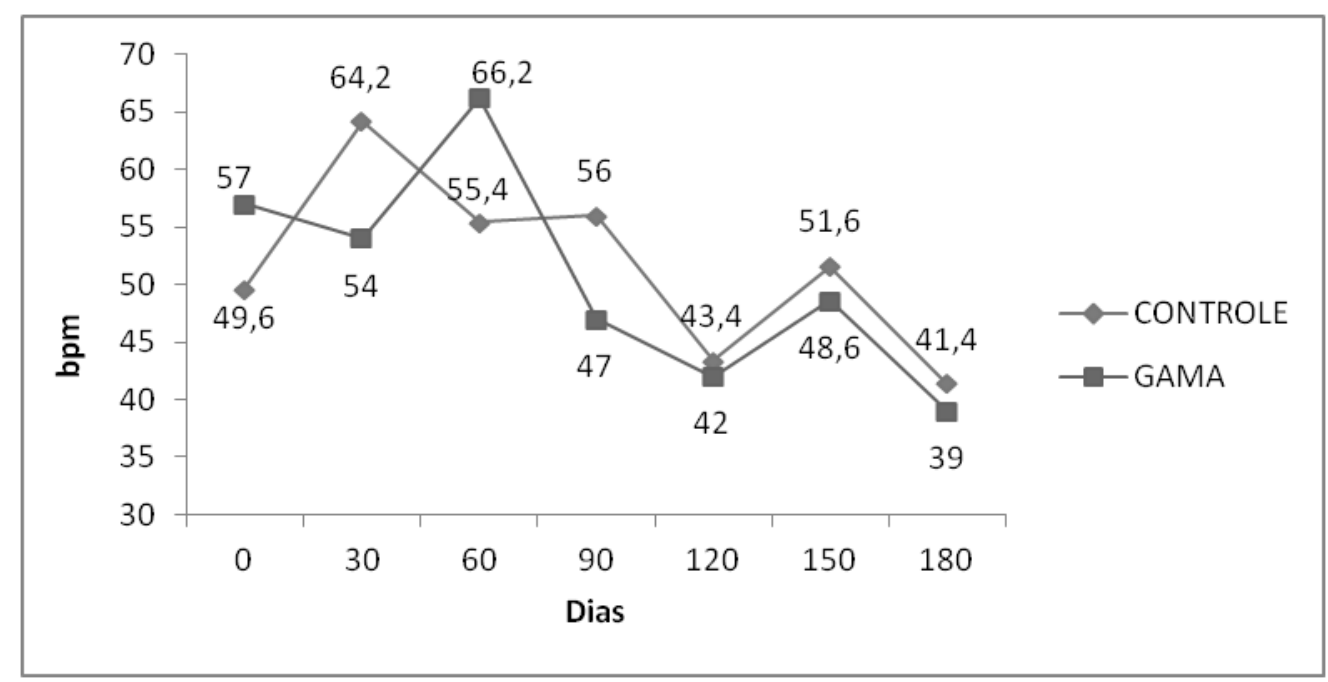


APÊNDICE M - Tabela 7 - Médias e desvio padrão da frequência cardíaca de recuperação, 20 minutos após o fim do exercício (em batimentos por minuto) do grupo controle e suplementado (gama), em função do tempo durante o período experimental

\begin{tabular}{cccc}
\multirow{2}{*}{ Tempo (dias) } & \multicolumn{2}{c}{ Tratamento } & \multirow{2}{*}{ CV (\%) } \\
\cline { 2 - 3 } & Controle & Gama & \\
\hline 0 & $46,80 \pm 4,82$ & $54,8 \pm 12,15$ & 19,06 \\
30 & $55,0 \pm 17,94$ & $48,2 \pm 4,76$ & 24,97 \\
60 & $45,0 \pm 3,81$ & $56,5 \pm 15,29$ & 22,89 \\
90 & $42,0 \pm 1,63$ & $43,6 \pm 5,32$ & 9,29 \\
120 & $43,4 \pm 4,51$ & $39,6 \pm 2,97$ & 9,92 \\
150 & $46,8 \pm 13,94$ & $43,4 \pm 13,54$ & 28,99 \\
180 & $43,6 \pm 5,46$ & $38,2 \pm 5,63$ & 14,55 \\
\hline
\end{tabular}


APÊNDICE N - Figura 6 - Frequência cardíaca de recuperação, em batimentos por minuto (bpm), 20 minutos após o final do exercício $(\mathrm{FC}+20)$ ao longo do tempo para os grupos controle e gama

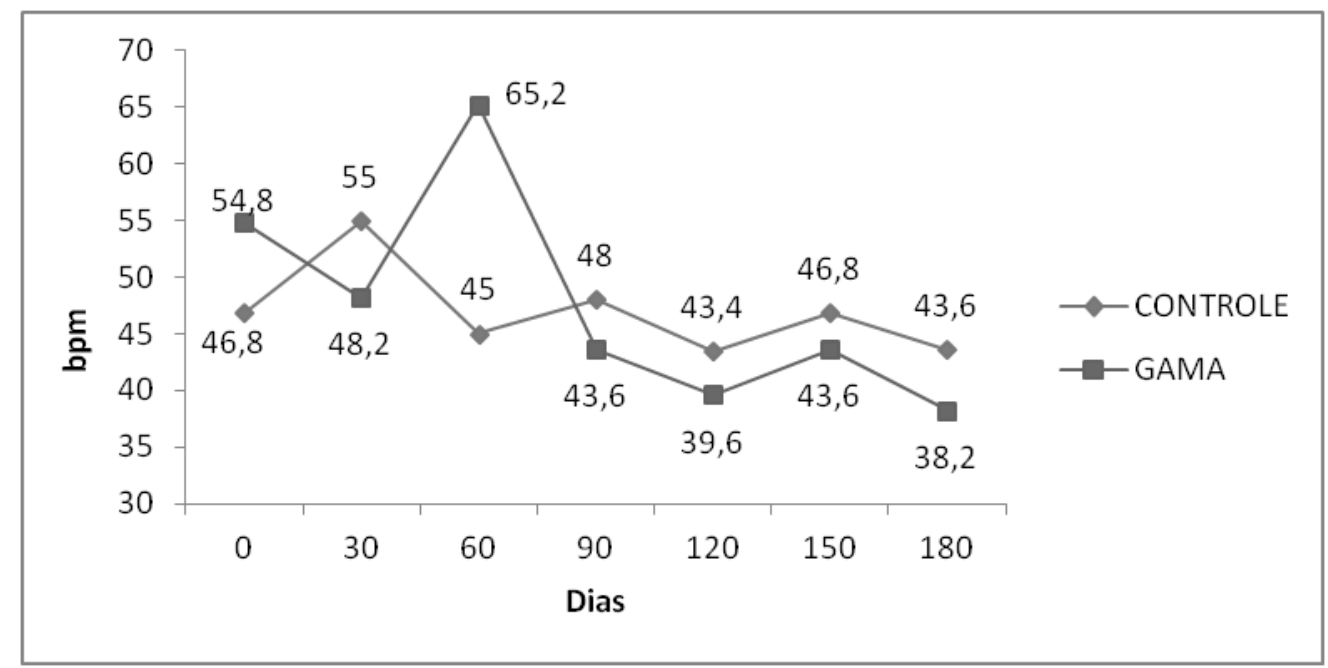


APÊNDICE O - Figura 7 - Frequência cardíaca (FC) média dos grupos controle e gama ao longo do período experimental no estágio 1 , a $7 \mathrm{Km} / \mathrm{h}$

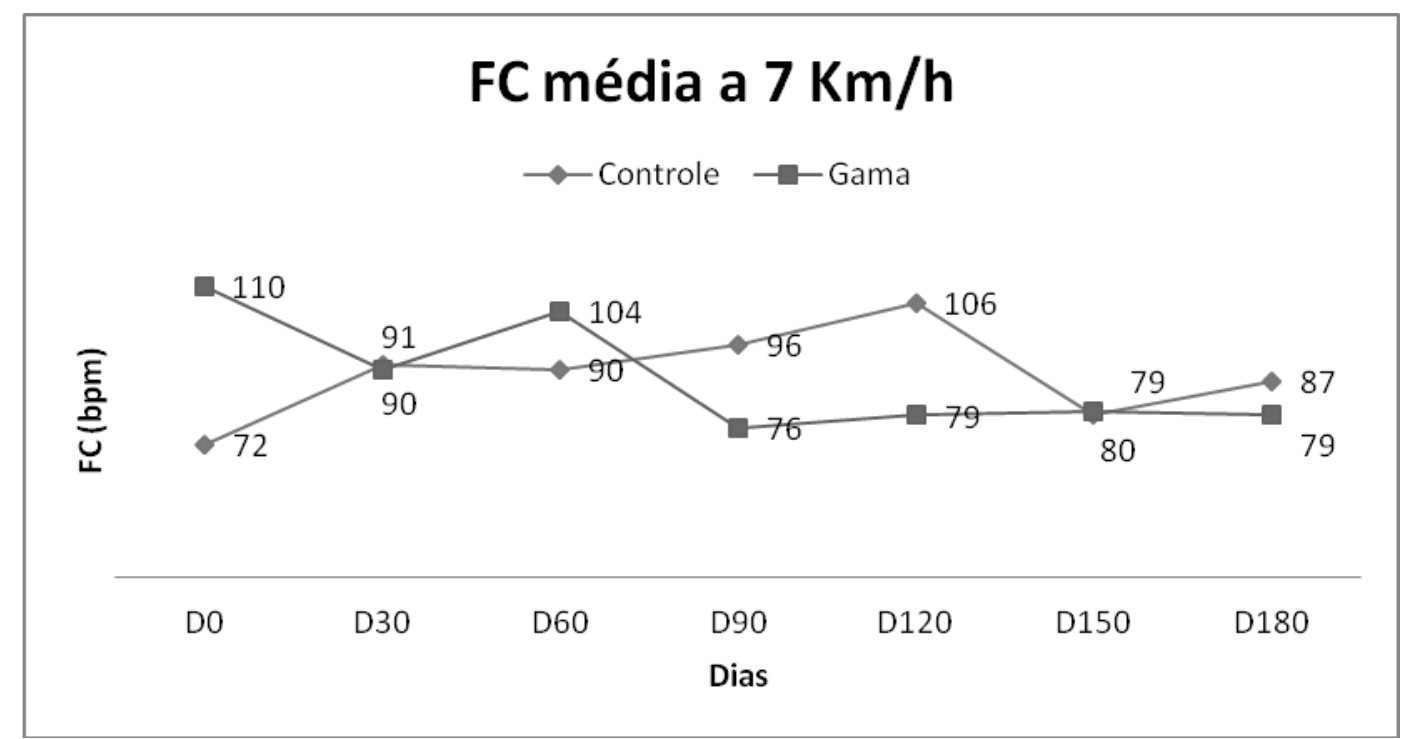


APÊNDICE P - Figura 8 - Frequência cardíaca (FC) média dos grupos controle e gama ao longo do período experimental no estágio 2 , a $10 \mathrm{Km} / \mathrm{h}$

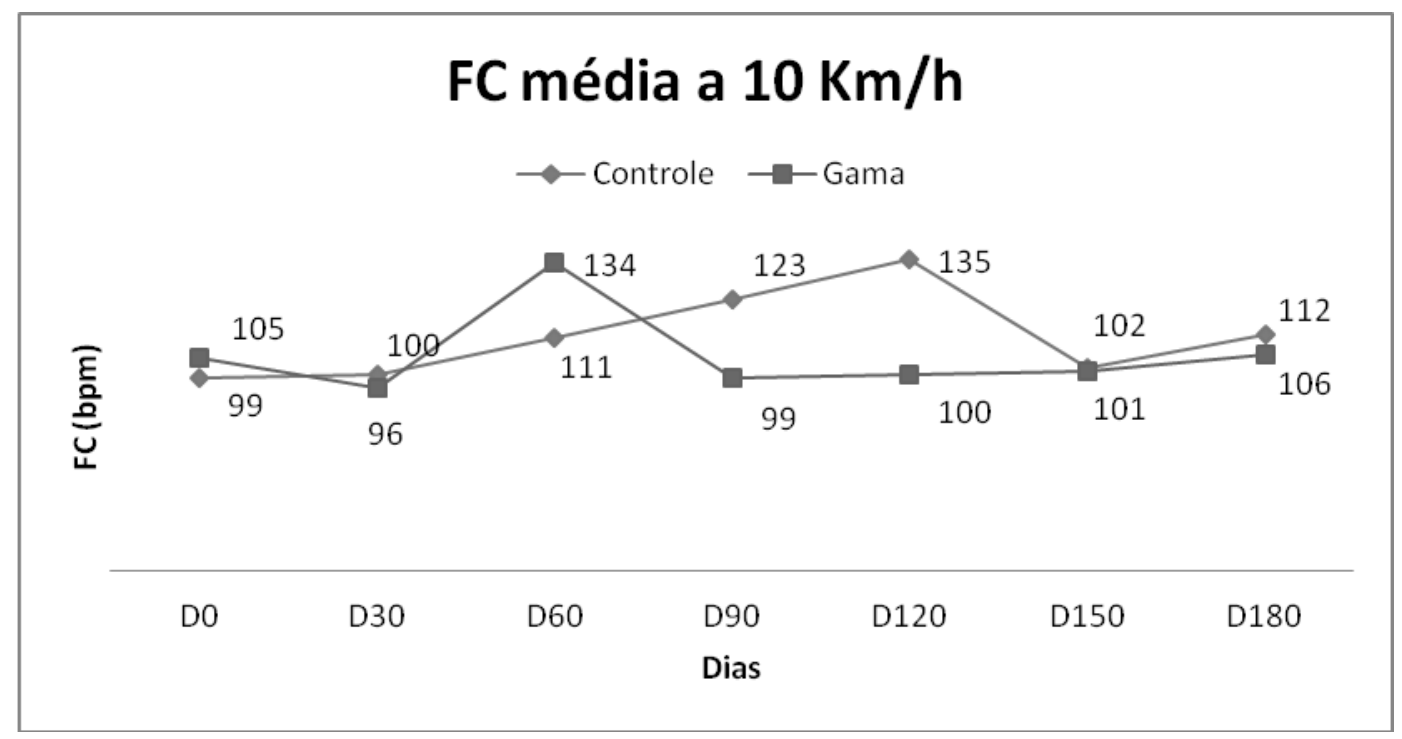


APÊEDICE Q - Figura 9 - Frequência cardíaca (FC) média dos grupos controle e gama ao longo do período experimental no estágio 3 , a $12 \mathrm{Km} / \mathrm{h}$

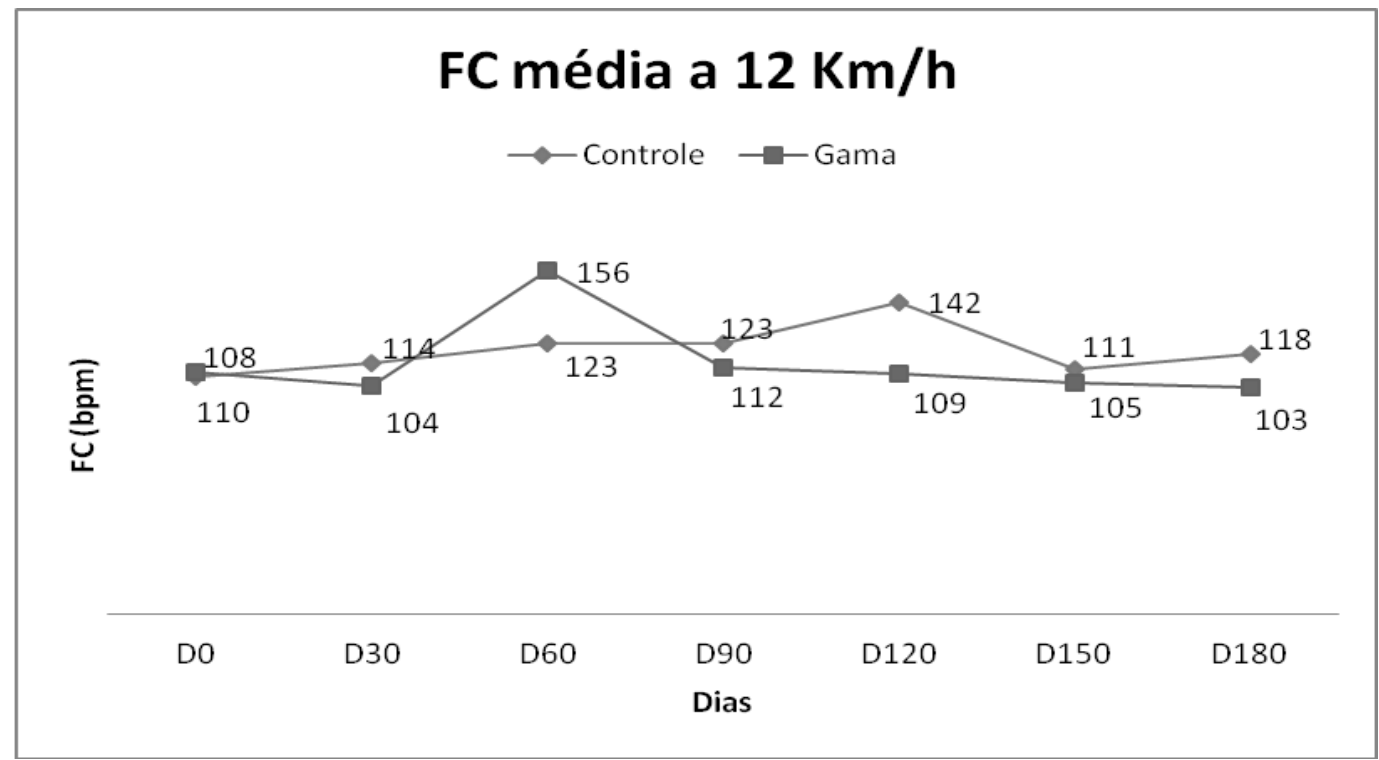


APÊNDICE R - Figura 10 - Frequência cardíaca (FC) média dos grupos controle e gama ao longo do período experimental no estágio 4 , a $12 \mathrm{Km} / \mathrm{h}$

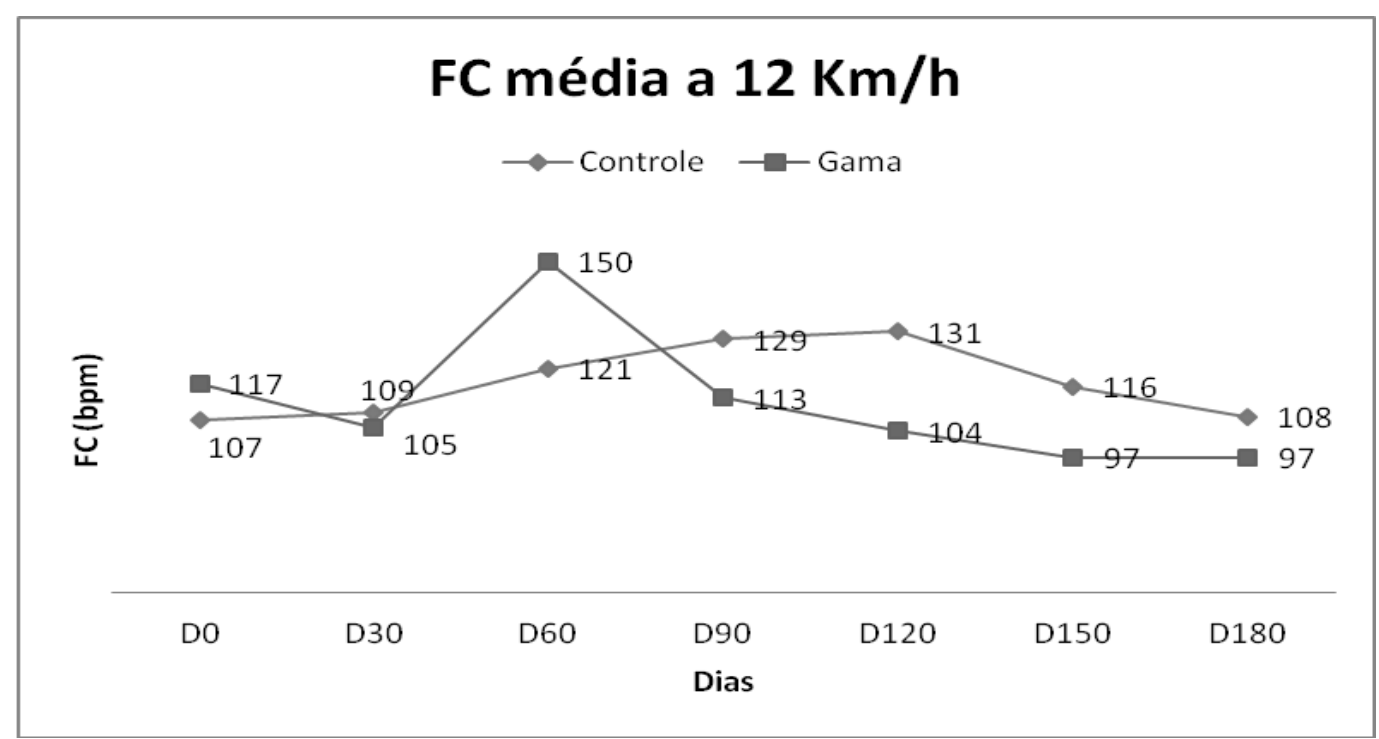


APENNDICE S - Figura 11 - Frequência cardíaca (FC) média dos grupos controle e gama ao longo do período experimental no estágio 5 , a $10 \mathrm{Km} / \mathrm{h}$

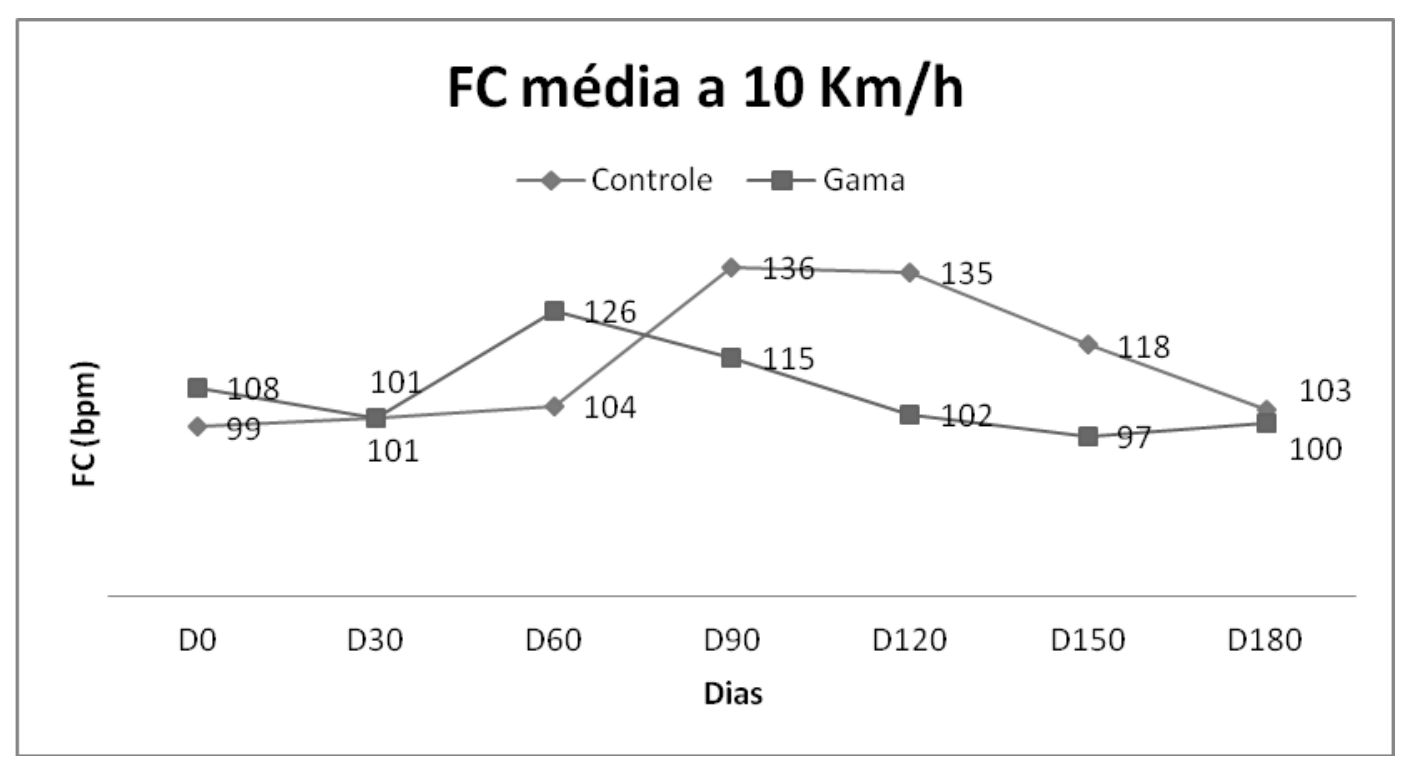


APÊNDICE T - Figura 12 - Frequência cardíaca (FC) média dos grupos controle e gama ao longo do período experimental no estágio 6 , a $7 \mathrm{Km} / \mathrm{h}$

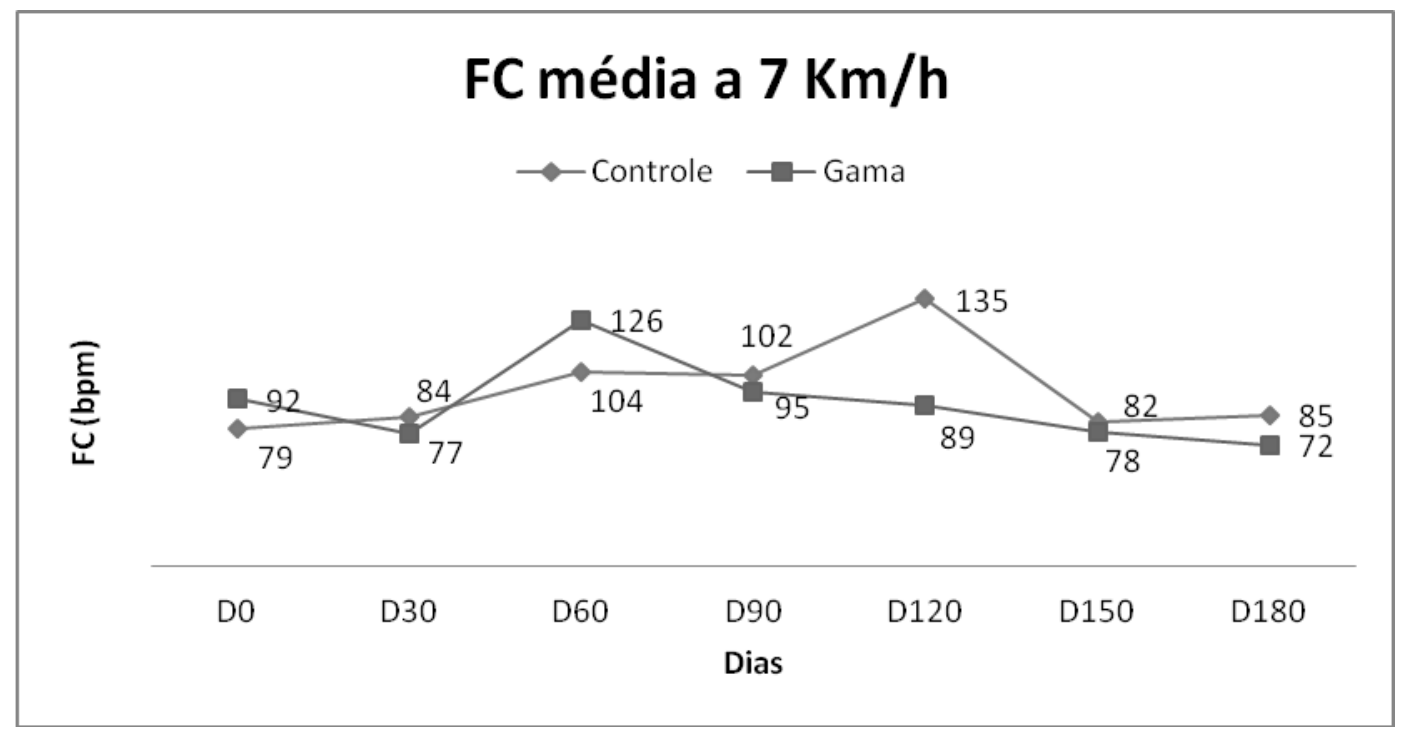


ANEXO 
ANEXO A - Figura 1 - Certificado de análise do gama-orizanol utilizado

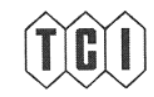

Certificate of Analysis

Printed on Aug/27/2011 (JST)

TOKYO CHEMICAL INDUSTRY CO.,LTD.

4-10-1 Nihonbashi-Honcho, Chuo-ku, Tokyo 103-0023 Japan *

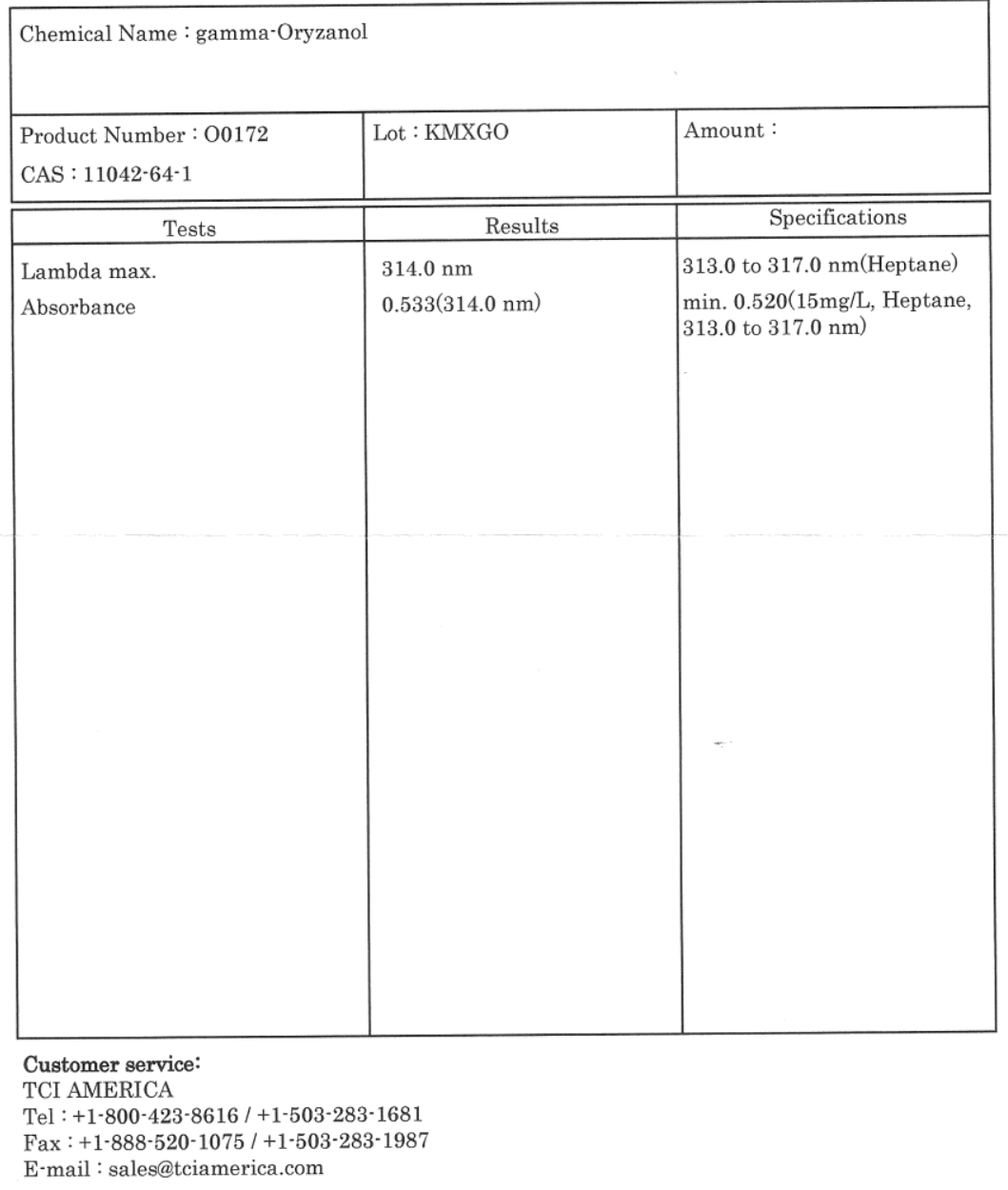

